\title{
The Hedging Channel of Exchange Rate Determination
}

Liao, Gordon and Tony Zhang

Liao, Gordon and Tony Zhang (2020). The Hedging Channel of

Exchange Rate Determination. International Finance

Discussion Papers 1283.

https://doi.org/10.17016/IFDP.2020.1283

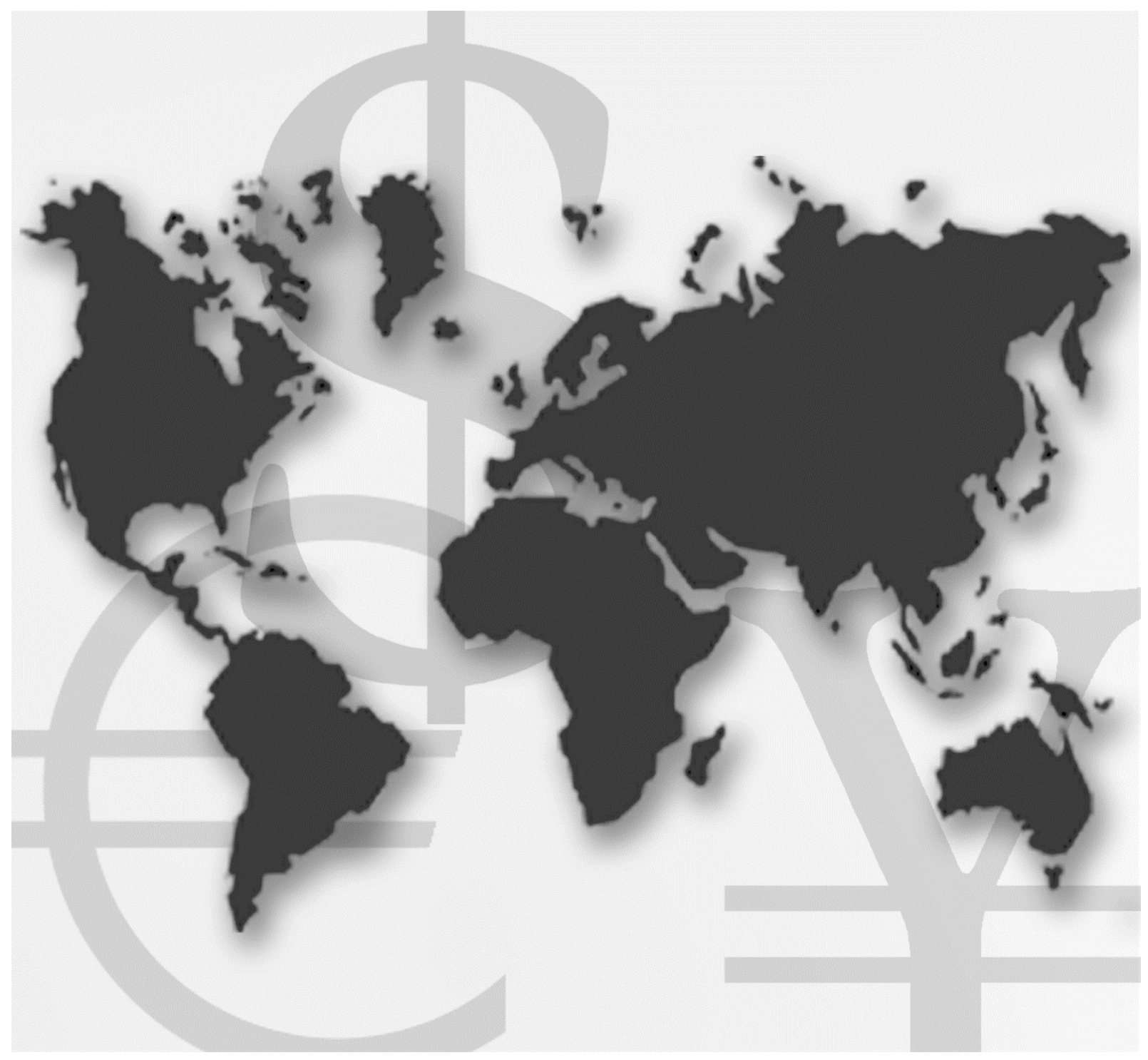

\section{International Finance Discussion Papers}

Board of Governors of the Federal Reserve System

Number 1283

May 2020 
Board of Governors of the Federal Reserve System

International Finance Discussion Papers

Number 1283

May 2020

\section{The Hedging Channel of Exchange Rate Determination}

Gordon Liao and Tony Zhang

NOTE: International Finance Discussion Papers (IFDPs) are preliminary materials circulated to stimulate discussion and critical comment. The analysis and conclusions set forth are those of the authors and do not indicate concurrence by other members of the research staff or the Board of Governors. References in publications to the International Finance Discussion Papers Series (other than acknowledgement) should be cleared with the author(s) to protect the tentative character of these papers. Recent IFDPs are available on the Web at www.federalreserve.gov/pubs/ifdp/. This paper can be downloaded without charge from the Social Science Research Network electronic library at www.ssrn.com. 


\title{
The Hedging Channel of Exchange Rate Determination *
}

\author{
Gordon Y. Liao ${ }^{\dagger} \quad$ Tony Zhang ${ }^{\ddagger}$
}

First Draft: April 2020

This Draft: May 2020

\begin{abstract}
We document the exchange rate hedging channel that connects country-level measures of net external financial imbalances with exchange rates. In times of market distress, countries with large positive external imbalances (e.g. Japan) experience domestic currency appreciation, and crucially, forward exchange rates appreciate relatively more than the spot after adjusting for interest rate differentials. Countries with large negative foreign asset positions experience the opposite currency movements. We present a model demonstrating that exchange rate hedging coupled with intermediary constraints can explain these observed relationships between net external imbalances and spot and forward exchange rates. We find empirical support for this currency hedging channel of exchange rate determination in both the conditional and unconditional moments of exchange rates, option prices, large institutional investors' disclosure of hedging activities, and central bank swap line usage during the COVID-19 market turmoil.
\end{abstract}

Keywords: Global imbalance, exchange rate, forward, hedging, covered interest rate parity, currency options, COVID19

JEL Classifications:E44, F31, F32, F41, G11, G15, G18, G20

${ }^{*}$ We thank Andrew Lilley for helpful suggestions. The views in this paper are solely the responsibility of the authors and should not be interpreted as reflecting the views of the Board of Governors of the Federal Reserve System or any other person associated with the Federal Reserve System.

†Liao: Board of Governors of the Federal Reserve System. Email: gordon.y.liao@frb.gov.

¥Zhang: Boston University Email: tzhang0@bu.edu. 


\section{Introduction}

The disconnect between exchange rates and macroeconomic variables remains one of the most persistent puzzles in international economics. In recent years, a growing body of evidence points to financial intermediary constraints and global imbalances as key drivers of exchange rate dynamics ${ }^{1}$. However, there is still relatively little understanding of the precise mechanisms that link exchange rates, the financial sector and macroeconomic variables. This paper proposes a mechanism that connects countries' net foreign asset positions to exchange rate markets. We show variation in investors' (and borrowers') desires to hedge exchange rate risks in their net foreign asset positions, along with intermediary frictions, explain a number of stylized facts in international financial markets.

Our proposed channel centers around exchange rate (FX) hedging activities. Figure 1 shows the hedge ratio of nine large Japanese life insurers on their foreign asset holdings against the Currency Volatility Index (CVIX) - a measure of implied exchange rate volatility analogous to the VIX Index. This figure highlights several common trends in the data. Foreign institutional investors have in recent years hedged a large fraction of the currency exposure on their foreign asset holdings through forwards and swaps. Their hedging behavior is time varying, and, moreover, their hedge ratio typically increases with currency volatility.

In this paper, we start by highlighting several novel facts that are consistent with a hedging channel of exchange rate determination. First, a large set of institutional investors and borrowers hedge a sizable portion of their currency mismatches. This set of participants has a particularly strong presence in the bond market, and is consistent with the finding from Liao (2019) that shows an increasing trend of currency-hedged corporate bond issuance

\footnotetext{
${ }^{1}$ For instance, Gabaix and Maggiori (2015) models exchange rate determination under limited financial intermediation; Jiang, Krishnamurthy, and Lustig (2019) emphasizes the role of safe asset demand; Lilley, Maggiori, Neiman, and Schreger (2019) documents reconnect between exchange rate movements and international investment positions in recent years.
} 


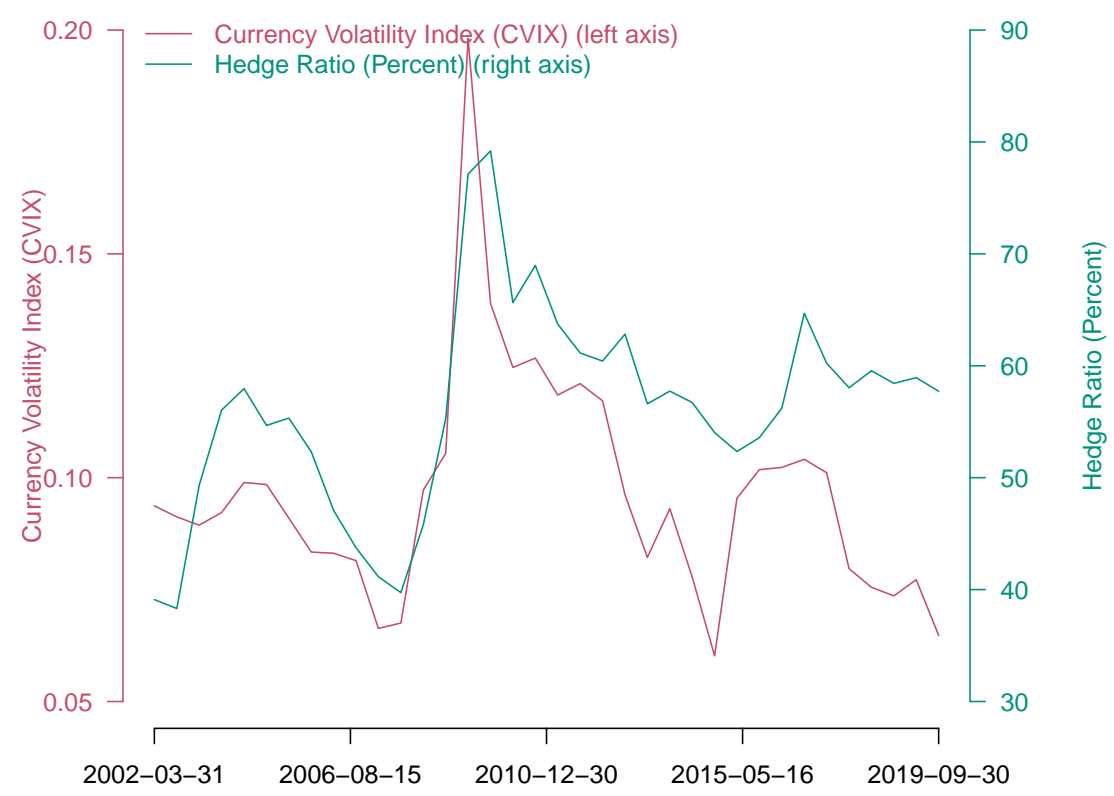

Notes: The hedge ratio is calculated by dividing the net notional amount of foreign currency forward and swap contracts (sold minus bought) by the foreign currency-denominated asset holdings reported in public disclosures of nine large Japanese insurers.

and Lilley et al. (2019) that highlights the relevance of bond purchase flow for exchange rate comovement.

Second, in countries with large positive external imbalances, as captured by their Net International Investment Positions (NIIP) and particularly their net debt and foreign direct investment (FDI) positions, the forward prices of domestic currency versus the U.S. dollar are unconditionally elevated relative to the spot price after adjusting for the interest rate differentials. This relative valuation between the forward and spot prices results in a currency basis, also known as a deviation from covered interest rate parity. ${ }^{2}$ In contrast, countries with large negative external imbalances generally observe an unconditional forward price of domestic currency that is depressed relative to the U.S. dollar.

\footnotetext{
${ }^{2} \mathrm{~A}$ non-zero cross-currency basis indicates a breakdown of covered interest rate parity condition as previously studied by Du, Tepper, and Verdelhan (2018) among others. In this paper, we emphasize the demand side in explaining the cross-sectional heterogeneity in the currency bases.
} 
Third, in periods of increased market volatility, countries with positive external imbalances experience domestic currency appreciation in both spot and forward exchange rate markets whereas countries with negative external imbalances experience currency depreciation. Moreover, forward exchange rates experience a greater magnitude of price movements relative to spot exchange rates after adjusting for interest rate differentials. This difference in exchange rate adjustment between the forward and the spot markets results in the increased cross-sectional dispersion of currency bases in line with the direction and magnitude of external imbalances.

To explain these stylized facts, we build a simple model of hedging demand and its impact on exchange rate markets. We consider a foreign country and an associated representative agent who owns a portfolio of U.S. dollar denominated assets. This foreign agent hedges a share of her net foreign asset position with forward (or swap ${ }^{3}$ ) contracts to stabilize the future payoff of her portfolio in domestic currency. If the agent is a net purchaser of foreign assets, then she hedges her exchange rate risk by selling dollars in the forward market. On the other hand, a net borrower hedges exchange rate risk by buying dollars forward. Hence, the quantity of dollar forwards demanded depends on the country's hedge ratio and net foreign asset position.

To satisfy investors' hedging demands, financial intermediaries produce forwards by trading the spot exchange rate along with the two countries' interest rates. Take for example Japan, which has substantial investor holdings of dollar assets and a positive foreign asset position. The representative Japanese investor hedges her exchange rate exposure by selling dollars and buying yen in the forward market with a financial intermediary. Hence, the financial intermediary must supply yen in the forward market.

However, the intermediary has alternative competing investment opportunities and therefore charges a spread for providing liquidity in the forward market. In our example, the

\footnotetext{
${ }^{3} \mathrm{~A}$ FX swap is composed of a spot and a forward transaction. A purchase of dollar against yen in the spot market and simultaneous selling of dollar versus yen in the forward market is equivalent to a swap of yen for dollar.
} 
forward price of the yen is elevated relative to spot exchange rate even after adjusting for interest rate differentials. The resulting spread is known as the cross-currency basis: the difference between the FX-implied yen interest rate and the actual yen interest rate. ${ }^{4}$ Our model highlights that the unconditional differences between a country's forward and spot exchange rate depend crucially on the magnitude and direction on the country's net external imbalances. Moreover, the magnitude of the difference between spot and forward exchange rates rise with the quantity of forwards that must be supplied, because the intermediary must be induced to devote more of her limited capital towards providing liquidity.

In times of economic distress, investor hedging demand combined with constrained financial intermediation generate predictable changes in forward and spot exchange rates. This occurs due to two factors. First, a rise in a country's hedge ratio increases the magnitude of the investor's demand for forwards in proportion to the country's net foreign asset position. Second, a rise in the constraints to financial intermediation leads to increases in the absolute level of bases required to induce intermediaries to provide liquidity. However, countries that are net savers should observe a currency basis in the opposite direction of countries that are net borrowers as their hedging demand differs in direction.

In addition to affecting the forward exchange rates, investor demand for forwards can spillover to the spot exchange rate market. Intermediaries that supply yen forward must buy yen in the spot market. As such, hedging pressure in the forward market imparts price pressure on spot exchange rates. In periods of market distress when the demand for either entering new hedges or rolling existing maturing hedges are large, hedging demand can drive the dynamics of both spot and forward exchange rate markets in predictable directions linked to countries' net external imbalances — spot exchange rate appreciates (depreciates) for countries with net positive (negative) external imbalance, but by an amount that is less than the changes in the forward exchange rate controlling for interest rate spreads.

\footnotetext{
${ }^{4}$ The FX-implied yen interest rate is the interest earned by converting yen into dollars, earning the dollar interest rate and converting the dollars back to yen at the forward exchange rate rate.
} 
In this sense, our model provides a potential explanation for the reconnect between spot exchange rates and macroeconomic variables since the Global Financial Crisis (Lilley et al., 2019). Our model contextualizes two ways in which the hedging channel has become more prominent since the Global Financial Crisis - increased currency hedge ratios of global investors and heightened balance sheet constraints for financial intermediaries. Additionally, we provide suggestive evidence that investment regulations and guidances for institutional investors, as well as optimization around the hedging of currency volatility contributed to a general increase in hedge ratios.

Furthermore, the hedging-driven demand for currencies during times of financial distress generate persistent differences in the returns to investing in different currencies. Currencies that appreciate in bad times earn a lower risk premia, as they provide a hedge against economic downturns. ${ }^{5}$ Our hedging channel posits a mechanism through which the crosssectional variation in currency excess returns is linked to global imbalances. ${ }^{6}{ }^{\text {The }}$ unconditional returns on currencies associated with countries with large positive external imbalances, e.g. Japan, is lower on average to compensate for the expected appreciation from hedging flows during times of distress.

Taking the model predictions to the data, we show support for the hedging channel of exchange rate determination in the behavior of both forward and spot exchange rates. In addition to the stylized facts discussed earlier, we draw on event studies of three crises - the COVID-19 Pandemic, the Eurozone crisis in 2011, and the Global Financial Crisis - and show that movements in forward and spot exchange rates are all consistent with increases in hedging demand during periods of financial distress.

Furthermore, we present evidence in the pricing of currency options that also points to the presence of the hedging demand consistent with our observations on forward exchange

\footnotetext{
${ }^{5}$ A growing literature identifies various country-level characteristics that could lead to differences in the stochastic properties of exchange rates. These characteristics include country size (Hassan, 2013), financial development (Maggiori, 2017), resilience to disaster risk (Farhi and Gabaix, 2016) and location in the trade network (Richmond, 2019).

${ }^{6}$ This link between external imbalances and currency excess returns has also been shown previously in DellaCorte, Riddiough, and Sarno (2016) and Wiriadinata (2020)
} 
rates. Countries with positive external imbalances can also hedge against domestic currency appreciation by buying call options on domestic currency. As a result, We find that out-ofthe-money call options on currencies with positive (negative) external imbalance generally have a premium (discount) over out-of-the-money puts. The relative pricing of puts and calls also varies across time, similar to currency basis spreads.

We formalize our case studies through a factor-based asset pricing test, and we show there is strong and predictable comovement between forward and spot exchange rates that is consistent with the currency hedging. We construct a risk-factor to proxy for changes in countries' hedging demands and the availability of financial intermediation: changes in the mean absolute magnitude of the cross-currency bases. We find that both spot and forward exchange rate returns load on this risk-factor consistent with measures of external imbalances. Additionally, our single-factor model explains a significant amount of variation in spot and forward returns as well as option skews over time.

Finally, we show countries' external imbalances also explain heterogeneity in the usage of dollar swap lines by different central banks during the COVID-19 market turmoil. These results highlight the importance of considering currency hedging when conducting central bank interventions. Currency regions with large positive external surpluses (e.g. the Euro area and Japan), need to borrow in dollars to produce domestic currency in the forward market for hedging purposes. As a result, we observe larger draws on the dollar liquidity swap lines in countries with large positive external imbalances, whereas regions with negative external imbalances had zero or little swap line usage.

Related Literature. Our paper is broadly inspired by the exchange rate disconnect literature. Since the influential work of Meese and Rogoff (1983), a long literature has tried to connect economic variables with exchange rates. Recent empirical work has found some predictive power using the cyclical component of net external balances (Gourinchas and Rey, 2007), investor capital flows (Evans and Lyons, 2002; Froot and Ramadorai, 2005; Camanho, Hau, and Rey, 2018), and quanto risk-premia (Kremens and Martin, 2019). More broadly, 
Lilley et al. (2019) and Lilley and Rinaldi (2020) show proxies for global risk appetite and risk premia explain a significant share of currency returns after the Global Financial Crisis. We contribute to this literature by linking the hedged part of investor portfolios to exchange rate dynamics, which helps explain the reconnect between spot exchange rates and external imbalances in recent years along with several additional facts.

From a theory perspective, our paper is most closely related to the literature studying portfolio balance effects in currency markets (Gabaix and Maggiori, 2015; Greenwood, Hanson, Stein, and Sunderam, 2019). The portfolio balance view argues for a quantity driven, supply-and-demand approach towards explaining asset prices, and has been successful in explaining puzzles in bonds (Vayanos and Vila, 2009; Greenwood and Vayanos, 2010; Krishnamurthy and Vissing-Jorgensen, 2011), swap spreads (Klinger and Sundaresan, 2019), mortgage-backed securities (Hanson, 2014), and equities (Shleifer, 1986). Most relevant to our paper is Gabaix and Maggiori (2015), who highlight the role of financial intermediary in determining spot exchange rates and Greenwood et al. (2019), who considers bond term premia and exchange rates jointly through a model of bond investors that operate in multiple markets. Relative to these studies, we highlight the demand-side factor and show that the currency hedging channel allows a reconnect of exchange rates to economic variables.

Finally, our paper relates to the growing body of literature studying the persistent violations of covered interest rate parity (Du et al., 2018). ${ }^{7}$ Others have shown the magnitude of CIP violations co-vary systematically with the broad dollar exchange rate (Avdjiev, Du, Koch, and Shin, 2019; Jiang et al., 2019; Engel and Wu, 2019). Our paper contributes to this literature in two ways: First, we explore a channel that connects macroeconomic fundamentals to the large cross-sectional dispersion observed in currency bases, and second, our proposed channel links forward and spot markets through intermediary activity.

\footnotetext{
${ }^{7}$ Other contributions to this strand of literature include Du, Im, and Schreger (2018); Liao (2019); Du, Hebert, and Huber (2019) among others.
} 


\section{Currency hedging and institutional details}

This section provides motivating evidence and institutional details for the use of currency hedges. Figure 1 showed large Japanese insurers substantially hedge their foreign asset portfolios against currency risk. This high currency hedge ratio is not unique to Japanese insurers, but rather is the norm among large non-U.S. institutional investors such as pensions and insurers. Many countries have regulations that restrict currency mismatch and encourages currency hedging for foreign assets. ${ }^{8}$ Additionally, the use of derivative instruments for currency hedging are often explicitly excluded from counting toward limits on derivative use. Post-global financial crisis rules for insurers, such as the Solvency II Directive, have also contributed to increased currency hedging. ${ }^{9}$ Furthermore, large corporate debt issuers in developed countries have been increasingly engaged in currency-hedged foreign debt issuance in order to obtain cheaper borrowing costs (Liao, 2019).

Table 1 summarizes the regulatory requirements on pension and insurance sectors and estimated FX hedging ratios for the countries associated with our sample of G-10 currencies. The regulations and currency match requirements are mainly applicable for large institutional investors such as pensions and insurers. These two sectors hold relatively large amounts of debt investments and have been documented to have a large impact on yield curve (Greenwood and Vissing-Jorgensen, 2018) and swap spreads (Klinger and Sundaresan, 2019). Australia additionally provides country-level surveys of foreign currency exposure and hedging, which shows a much higher level of hedging for debt relative to equities. Even absent of regulations, the high hedging ratio for debt is unsurprising since exchange rate risk is large relative to fixed income returns but small relative to equity returns and the risk-minimizing currency strategy for a global bond investor is close to a full currency hedge(Campbell,

\footnotetext{
${ }^{8}$ For instance, pension investment regulations in Germany, Switzerland, Denmark and Italy each mandate at least $70 \%$ to $80 \%$ currency matching between assets and liabilities (OECD Survey of investment regulation of pension funds, 2019).

${ }^{9}$ The Solvency II Directive imposes a capital charge (usually $25 \%$ ) on currency mismatches of European and U.K. insurers.
} 
Serfaty-De Medeiros, and Viceira, 2010). Motivated by this evidence, we employ measures of external imbalance that excludes equity portfolio holdings.

Compared to earlier surveys that showed little currency hedging by U.S. institutional investors (Levich, Hayt, and Ripston, 1999), these new evidence suggests a possible change in currency markets and distinction between equity and debt investors. The increase in hedging practices potentially contributed to the liquidity and turnover of hedging instruments — the volume of exchange rate hedging instruments (forwards and swaps) has surpassed those of spot transactions in recent years. Figure 2 shows the daily average turnover of the global exchange rate market by currency and instrument based on the Triennial FX Survey published by the Bank of International Settlements. Notably, swap and forward volumes are larger than the spot. In 2019, the forward and swap daily average volume was $136 \%$ of spot volume.

Why do investors choose to hedge via forwards and swaps instead of trading spot exchange rates? The use of currency forwards as a portfolio adjustment tool is analogous to the use of equity and bond futures by institutional investors to adjust their overall market and duration risks without shifting out of their cash investments. Investors reducing currency exposure via spot transactions would need to also sell their cash asset holdings in the foreign currency. On the other hand, hedging via currency forwards doesn't require liquidating asset holdings. In times of market stress, the use of currency forwards for the reducing currency risk would be optimal even if the investor intends on eventually selling their foreign asset holdings, but desires to avoid poor market liquidity for cash assets.

\section{Model}

In this section, we present a model of exchange rate determination that links hedging demand and external imbalances to the cross-currency basis, the forward exchange rate and the spot 
exchange rate. We make a number of simplifying assumptions to keep our model tractable and focused on the relationships of interest.

Two time periods exist, $t=1,2$. We focus on a representative investor in a foreign country whose second period portfolio payoff is exposed to fluctuations in the value of the dollar. For simplicity, we call the foreign country Japan and its currency the yen. The asset space only consists of risk-free government bonds denominated in dollars and yen. Both the dollar risk-free rate, $1+r_{D, 1}$, and the yen risk-free rate, $1+r_{Y, 1}$, are given exogenously. At the end of period 1, we assume Japan has a net external position of $X_{D, 1}$ in U.S. governments bonds that earn the risk-free return $1+r_{D, 1}$. In period 2 , the Japanese investor wants to convert her dollar position into yen for consumption. We let $S_{1}$ denote spot exchange rate in period 1 , and $F_{1,2}$ denote the forward rate in period 1 that matures in period 2. Both $S_{1}$ and $F_{1,2}$ are quoted in terms of foreign currency per dollar (i.e. yen per dollar).

\subsection{Demand for Forward Dollars}

The Japanese investor hedges her exchange rate exposure by trading dollars in the forward market. If the Japanese investor has a positive external imbalance $\left(X_{D, 1}>0\right)$, then she receives dollars in period 2 and wants to exchange those dollars into local currency. Hence, she hedges by selling dollars in the forward market. On the other hand, if the Japanese investor has a negative external imbalance $\left(X_{D, 1}<0\right)$, then she owes dollars in period 2 and hedges her exposure by buying dollars in the forward market.

For simplicity, we further assume the Japanese investor hedges an exogenous fraction $h$ of her external imbalance. Hence, the Japanese investor demands:

$$
\text { Demand for forward dollars }=-h X_{D, 1}\left(1+r_{D, 1}\right)
$$

dollars in the forward market. By taking $h$ as exogenous, we first analyze how changes in the investor's hedge ratio affect exchange rate markets without simultaneously analyzing the 
determinants of the hedge ratio itself. Appendix A.1 provides an extension in which the Japanese investor endogenously choose her optimal hedge ratio $h$ in response to her external imbalance and expected exchange rate volatility.

\subsection{Supply of Forward Dollars and CIP}

There exists a currency swap trader who chooses to devote capital to either providing liquidity in the forward dollar market, or to alternative investment opportunities that provides profit $G(I)$ for an investment of $I$. This currency swap trader has wealth $W$ denominated in yen in period 1.

We start by describing the two types of trades that the swap trader engages in to produce currency on the forward market. To reiterate, if $X_{D, 1}>0$, then the Japanese investor sells dollars in the forward market, and the swap trader supplies yen. Hence, the swap trader takes a positive position of $q_{1}$ yen in period 1 and produces $q_{1}\left(1+r_{Y, 1}\right)$ yen on the forward market to exchange for dollars. In order to fund the initial position of $q_{1}$ yen, the swap trader borrows $q_{1} / S_{1}$ dollars at the dollar risk-free rate $1+r_{D, 1}$. In period 2 , the swap trader exchanges her yen for the Japanese investor's dollars and pays back her dollar loan. Ultimately, the swap trader earns a profit of:

$$
\text { Swap trader profit }=q_{1}\left(\left(1+r_{Y, 1}\right)-\frac{F_{1,2}}{S_{1}}\left(1+r_{D, 1}\right)\right)
$$

yen from this transaction in period 2 .

Now suppose $X_{D, 1}<0$, and the Japanese investor buys dollars in the forward market. To produce dollars for the forward market, the swap trader buys dollars by borrowing in yen $\left(q_{1}<0\right)$. The swap trader earns the dollar interest rate of $1+r_{D, 1}$ on her $-q_{1} / S_{1}$ dollars. In period 2, the swap trader sells $-q_{1}\left(1+r_{D, 1}\right) / S_{1}$ dollars to the Japanese investor, receives $-F_{1,2} q_{1}\left(1+r_{D, 1}\right) / S_{1}$ yen and pays back $-q_{1}\left(1+r_{Y, 1}\right)$ from her initial position. As a result of this transaction, the swap trader's profit is again given by equation (2). 
We define the cross-currency basis, $b_{1}$, as the spread between the exchange rate implied yen risk-free rate and the actual yen risk-free rate:

$$
b_{1}=\underbrace{\frac{F_{1,2}}{S_{1}}\left(1+r_{D, 1}\right)}_{\text {FX-implied yen risk-free rate }}-\underbrace{\left(1+r_{Y, 1}\right)}_{\text {Actual yen risk-free rate }} .
$$

The currency swap trader earns $-q_{1} b_{1}$ on an initial position of $q_{1}$ yen. The currency swap trader provides liquidity in forward markets only when it is profitable: $-q b_{1} \geq 0$.

Following Gârleanu and Pedersen (2011) and Ivashina, Scharfstein, and Stein (2015), we assume the swap trader must set aside a haircut $H_{1}=\kappa\left|q_{1}\right|$ when she devotes $q_{1}$ yen to provide forward dollars. Hence, the swap trader is left with $I_{1}=W-\kappa\left|q_{1}\right|$ yen to devote to alternative investments. The swap trader faces the following investment decision:

$$
\max _{q_{1}}-b_{1} q_{1}+G\left(W-\kappa\left|q_{1}\right|\right)
$$

The swap trader's first order condition shows the gain from devoting an additional unit of capital to providing liquidity in the forward dollar market is equal to the marginal profitability of the alternative investment:

$$
b_{1}=-\operatorname{sign}\left[q_{1}\right] \kappa G^{\prime}\left(W_{1}-\kappa\left|q_{1}\right|\right)
$$

For tractability, we follow Liao (2019) and make the following additional simplifying assumptions about the functional form of $G$ : $G\left(I_{1}\right)=\psi_{1} I_{1}-\frac{1}{2} \phi I_{1}^{2}, \psi_{1}=\phi W$ and $\phi=1$. Together, these assumptions imply that the swap trader has just enough wealth to take advantage of all positive-NPV investment opportunities in the alternative investment. These assumptions imply the basis is directly proportional to the swap trader's position: $b_{1}=$ $-\kappa^{2} q_{1} \cdot{ }^{10}$

\footnotetext{
${ }^{10}$ This model of swap traders is analogous to Ivashina et al. (2015), which imposes a log functional form for the profits from the alternative investment rather than quadratic.
} 
The swap trader's first order condition shows the cross-currency basis $b_{1}$ is a result of two forces: The Japanese investor's hedging and the costs of financial intermediation. If the Japanese investor does not demand dollars in the forward market, then $q_{1}=0$ and the basis reduces to zero. Similarly, if there were no costs to providing liquidity in the forward market $\kappa=0$, then the basis reduces to zero as well. Hence, when financial intermediation is costly $(\kappa>0)$, the swap trader does not supply enough forward contracts to fully eliminate the difference between the exchange rate implied yen risk-free rate and the actual yen risk-free rate.

\subsection{Spot Exchange Rates}

We assume the dollar-yen spot exchange rate in each period clears the market for dollars:

$$
\frac{q_{1}}{S_{1}}+\frac{\xi_{Y, 1}}{S_{1}}-\iota_{D, 1}=0
$$

where $\xi_{Y, 1} / S_{1}$ represents additional demand for dollars and $\iota_{D, 1}$ represents the supply of dollars provided by other sectors of economy that are not modelled. Both $\xi_{Y, 1} / S_{1}$ and $\iota_{D, 1}$ are positive $(>0)$ and are accounted for in dollars. As an example, Gabaix and Maggiori (2015) provide a model of exchange rate determination in which the net demand for dollars is a function of goods trade as well as financial flows. In such a model, $\left(\xi_{E, 1} / S_{1}\right)-\iota_{D, 1}$ represents the net exports from the U.S. to Japan. The unmodeled residual net demand can also originate from the financial sector. For instance, $\iota_{D, 1}$ can represent the supply of dollar by a broad set of financial intermediaries that takes on exchange rate risk and engages in fixed income arbitrage activities across global bond markets as modeled in Greenwood et al. $(2019) \cdot{ }^{11}$

\footnotetext{
${ }^{11}$ The swap trader modeled above differs in that they only arbitrage CIP deviation and does not take on exchange rate risk. Such specialization can reflect market segmentation in arbitrage activities and differences in the level of risk tolerance, sophistication, and capital cost in providing arbitrage.
} 


\subsection{Equilibrium and Model Predictions}

In equilibrium, the swap trader takes the hedging demand of the Japanese investor as given, and enters into swap transactions to supply dollars in the forward market:

$$
q_{1}=h X_{D, 1} S_{1}
$$

Market clearing conditions in the forward and spot exchange rate markets determine the cross-currency basis $b_{1}$, the forward rate $F_{1,2}$, and the spot exchange rate $S_{1}$ as a function of the hedge ratio $h$, Japan's external imbalance $X_{D, 1}$, and the demand for dollars and yen from other sectors of the economy, $\iota_{D, 1}$ and $\xi_{Y, 1}$. The equilibrium is described by the following three equations:

$$
\begin{aligned}
b_{1} & =-\frac{h \kappa^{2} X_{D, 1} \xi_{Y, 1}}{\iota_{D, 1}-h X_{D, 1}} \\
F_{1,2} & =\frac{\xi_{Y, 1}\left(1+r_{Y, 1}\right)}{\left(\iota_{D, 1}-h X_{D, 1}\right)\left(1+r_{Y, 1}\right)}-\frac{\xi_{Y, 1}^{2} \kappa^{2} h X_{D, 1}}{\left(\iota_{D, 1}-h X_{D, 1}\right)^{2}\left(1+r_{D, 1}\right)} \\
S_{1} & =\frac{\xi_{Y, 1}}{\iota_{D, 1}-h X_{D, 1}}
\end{aligned}
$$

We use equations (6)-(8) to analyze the effect of hedging demand on exchange rate markets, and we start by studying the dynamics of the cross-currency basis. While the crosscurrency basis may not be the most salient price in exchange rate markets, it nevertheless provides the relative valuation between forward and spot exchange rates that reflects hedging

demand and intermediary constraints. Unlike the cross-currency basis, the dynamics of spot or forward exchange rates can be contaminated by movements in other variables such as interest rates.

We first relate a country's external imbalance to the spread earned by swap traders for providing liquidity to its representative investor. 
Prop 1. (Unconditional currency basis) A country's cross-currency basis, $b_{1}$, is inversely related to its external imbalance, $X_{D, 1}^{i}$ :

$$
\frac{\partial b_{1}}{\partial X_{D, 1}}=-\frac{h \iota_{D, 1} \xi_{Y, 1} \kappa^{2}}{\left(\iota_{D, 1}-h X_{D, 1}\right)^{2}} .
$$

A country with a positive external imbalance $\left(X_{D, 1}>0\right)$ has a negative basis $\left(b_{1}<0\right)$, and a country with a negative external imbalance $\left(X_{D, 1}<0\right)$ has a positive basis $\left(b_{1}>0\right)$.

Proposition 1 shows a country's unconditional currency basis is a direct measure of the country's external financial imbalance and its investors' desires to hedge this imbalance. Netlender countries should observe negative currency bases because the swap trader provides liquidity by borrowing at the FX-implied foreign risk-free rate. Net-borrow countries should observe positive currency bases because the swap trader provides liquidity by borrowing at the actual foreign risk-free rate. Larger external financial imbalances requires the swap trader to provide more liquidity. In return the swap trader earns a larger spread on her position.

A log-linear approximation of equation (3) shows the log forward rate is approximately equal to the cross-currency basis plus the log spot exchange rate after adjusting for interest rate differentials:

$$
f_{1,2} \approx b_{1}+s_{1}+\left(r_{Y, 1}-r_{D, 1}\right) .
$$

Countries with positive external imbalances experience negative bases $\left(b_{1}<0\right)$, and the forward price of their domestic currency is unconditionally elevated relative to the spot price after adjusting for interest rate differentials. Intuitively, investors in countries with positive external imbalances demand domestic currency in forward markets for hedging purposes, and therefore must pay a premium to purchase domestic currency in the forward market because producing currency forward is costly. Conversely, countries with negative external imbalances have forward exchange rates that are unconditionally depressed relative to their 
spot. Investors in countries with negative external imbalances demand dollars in forward markets, and must pay a premium to exchange domestic currency for dollars forward.

Prop 2. (Conditional currency basis) Increases in hedging demand, $h$, and increases in the cost of financial intermediation both increase the magnitude of the currency basis, $b_{1}$ :

$$
\frac{\partial b_{1}}{\partial h}=-\frac{X_{D, 1} \iota_{D, 1} \xi_{Y, 1} \kappa^{2}}{\left(\iota_{D, 1}-h X_{D, 1}\right)^{2}}, \text { and } \frac{\partial b_{1}}{\partial \kappa}=-\frac{2 h X_{D, 1} \xi_{Y, 1} \kappa}{\iota_{D, 1}-h X_{D, 1}}
$$

A country with a more positive external imbalance observes a larger decrease (smaller increase) in their basis:

$$
\frac{\partial^{2} b_{1}}{\partial X_{D, 1} \partial h}=-\frac{\left(\iota_{D, 1}+h X_{D, 1}\right) \iota_{D, 1} \xi_{Y, 1} \kappa^{2}}{\left(\iota_{D, 1}-h X_{D, 1}\right)^{3}}<0, \text { and } \frac{\partial^{2} b_{1}}{\partial X_{D, 1}^{i} \partial \kappa}=-\frac{2 h X_{D, 1}^{i} \iota_{D, 1} \xi_{Y, 1} \kappa}{\left(\iota_{D, 1}-h X_{D, 1}^{i}\right)^{2}}<0 .
$$

Increases in a country's hedge ratio and the cost of financial intermediation have the same qualitative effect on the magnitude of currency bases: both increase the magnitude of the cross-currency basis. A larger hedge ratio forces the swap trader to take a larger position, $q$, to provide the demanded liquidity. Increases in the cost of financial intermediation directly increase the per unit costs of providing liquidity. In times of financial distress, it is likely that both forces affect the currency basis. For example, Figure 1 showed that Japanese life insurance companies systematically raised and lowered their hedge ratio in accordance with volatility in the dollar-yen exchange rate. Additionally, Du et al. (2018) showed currency bases are partially driven by bank balance sheet costs.

Crucially, however, proposition 2 shows a country's external imbalance identifies the direction of movements in forward and spot exchange rates in times of financial distress. If $X_{D, 1}>0$, then $b_{1}$ becomes more negative and the country's forward exchange rate becomes even more elevated relative to the spot exchange rate. Alternatively, if $X_{D, 1}<0$, then $b_{1}$ becomes more positive and further depresses the forward rate. 
Next, we turn to the spot exchange rate market. Hedging demand in the forward market impacts the spot market, because swap traders transact in spot exchange rate markets in the production of forward currencies.

Prop 3. (Spot exchange rate) An increase in a foreign country's hedge ratio, $h$, impacts the country's spot exchange rate in proportion to its external imbalance:

$$
\frac{\partial S_{1}}{\partial h}=-\frac{X_{D, 1} \xi_{Y, 1}}{\left(\iota_{D, 1}-h X_{D, 1}\right)^{2}}
$$

In times of financial distress, investors increase their hedge ratio in response to increased exchange rate volatility. Swap traders use dollars to purchase additional units of foreign currency to satisfy the additional demand in forward markets from countries with positive

external imbalances. As a results, countries with large positive external imbalances experience domestic currency appreciation. By similar logic, countries with large negative foreign asset positions experience domestic currency depreciation.

Proposition 3 shows the magnitude of the effect of swap trader activity on spot exchange rate markets is directly proportional to the relative magnitude between the demand for dollars originating from hedging demand, and the demand for dollars from other sectors of the economy. Naturally, as the quantity of dollars required for hedging services increases, increases in the hedge ratio and swap trader activity have larger impacts on the spot exchange rate.

\subsection{Central Bank Swap Lines}

Our model also identifies the channels through which central bank swap lines alleviate funding conditions and sheds light on its limitations. Federal Reserve swap lines provide dollar funding to the broader market by lending dollars to foreign central banks. These foreign central banks, in turn, lend dollars from the swap line to domestic institutions on a collat- 
eralized basis. Liquidity provision through the swap line impacts the prices of forward and spot exchange rates as dollar lending via the swap line is equivalent to providing dollars in the spot market in exchange for foreign currency, and simultaneously repurchasing dollars in forward markets. Previous studies have shown that central bank swap lines are effective tools at reducing the currency basis (Goldberg, Kennedy, and Miu, 2010; Bahaj and Reis, 2018).

Our model suggests that swap lines alleviate funding conditions through three main channels. First, the direct provision of dollar loans against foreign currency collateral temporarily reduces a foreign counterparty's net foreign asset position $X_{D, 1}$. Second, the announcement of swap lines may instill more confidence in the financial sector and lower the overall balance sheet $\operatorname{costs} \kappa$ for swap intermediaries that are producing forward contracts. Third, the general provision of dollar liquidity can also reduce capital retrenchment and dollar hoarding, thereby reducing possible future exchange rate volatility and lowering institutional hedging demand $h$. Mapping the channels to the model predictions, lowering $X_{D, 1}$ leads to the reduction of currency basis for countries with positive net foreign asset positions, e.g. Japan, as shown in Proposition 1. By lowering $\kappa$ and $h$, the Fed can decrease the magnitude of all currency bases regardless of direction, as Proposition 2 shows.

If an increase in $h$ were the main driver for swap line usage, countries with negative external imbalances, which demand dollars in the forward market, should have minimal draws on their Federal Reserve swap line. This is because the swap line provides dollars today and requires repayment in dollars at a later date. Notably, this prediction runs counter to the intuition that large debtor countries are most in need of dollars in times of stress.

\subsection{Term Structure of Currency Basis}

Appendix A.2 extends the benchmark model by an additional period in order to study the term structure of currency bases under the presence of uncertainty in hedging demand. We let there be three time period, $t=1,2,3$. The Japanese investor still has a net external 
imbalance of $X_{D, 1}$ in period 1, but she now wants to hedge the yen payoff of her position in period 3. The Japanese investor can either trade dollars two periods forward, or trade dollars one period forward and then roll over her hedge position in period 2.

In period 2, the swap trader faces uncertainty in the Japanese investor's hedging demand. With probability $\pi$ the hedging demand $h$ in period 2 equals $h_{L}$ and with probability $1-\pi$ the hedging demand in period 2 equals $h_{H}$. Solving the swap trader's profit maximization problem shows the currency basis on the two-period forward is a weighted average of the one-period bases in periods 1 and 2:

$$
b_{1}^{(2)}=\frac{b_{1}\left(1+r_{Y, 2}\right)}{2}+\frac{\pi b_{2, L}+(1-\pi) b_{2, H}}{2}
$$

where $b_{1}^{(2)}$ is the currency basis on the forward contract maturing in period $3 . b_{1}^{(2)}$ represents the swap trader's profit in period 3 on each unit of capital she devotes to providing liquidity in the period 3 forward market. $b_{1}$ is the one-period currency basis in period 1 , and $b_{2, k}$ is the one-period basis in period 2 when the hedging demand equals $h_{k}$ for $k=L, H$. $1+r_{Y, 2}$ is the one-period risk-free rate in period 2 .

Equation (9) has a very natural interpretation. The first term on the right-hand side, $b_{1}\left(1+r_{Y, 2}\right) / 2$ represents the contribution of the period 1 currency basis to $b_{1}^{(2)}$. $b_{1}$ is the swaps trader's profit in period 2, and grows at the rate $1+r_{Y, 2}$ from period 2 to period 3. The second term on the right-hand side of equation (9) captures the expected period 2 currency basis.

Equation (9) reveals the slope of the currency basis term structure depends on the expected period 2 basis relative to the period 1 basis. If, in expectation, the currency basis is expected to increase in magnitude from period 1 to period 2, then the two-period basis $b_{1}^{(2)}$ should be larger in magnitude than the period 1 basis $b_{1}$. Propositions 2 showed currency bases increase in response to increases in hedging demand or increases in the costs of financial intermediation. Hence, we should expect currency bases to increase in magnitude 
with maturity whenever the current magnitude of currency bases are relatively low (and are therefore likely to increase in the future given a sufficiently high $\pi$ ). Conversely, we should expect currency bases to decrease in magnitude with maturity whenever the current magnitude of currency bases are relatively high.

\section{Measures of hedging demand}

Having provided intuition for the effects of currency hedging on forward and spot exchange rates, we now turn to empirical analysis to test model predictions. We focus on the G10 currency regions: Australia (AUD), Canada (CAD), Switzerland (CHF), the Euro area (EUR), the United Kingdom (GBP), Japan (JPY), Norway (NOK), New Zealand (NZD), Sweden (SEK) and the United States (USD). These currencies are the most liquid and commonly traded free-floating currencies without significant capital control impediments. ${ }^{12}$

We measure the quantity of external imbalances at the country level using data on Net International Investment Position (NIIP) and its constituent components obtained from the International Monetary Fund's International Financial Statistics data set. We focus our main analysis on two measures in particular: The aggregate NIIP, and the net debt and foreign direct investment (FDI) components of NIIP. ${ }^{13}$ Both measures are scaled by nominal GDP. In particular, Section 1 showed external imbalances in debt and FDI positions are more likely to reflect hedging demand, because these investment types are dominated by institutional investors that hedge a greater fraction of their currency exposure either due to regulations or risks. 14

To measure the price impact of hedging external imbalances, we mainly focus on the cross-currency basis that captures the relative valuation of forward and spot exchange rates

\footnotetext{
${ }^{12}$ The Chinese Yuan and Hong Kong dollar are also among the most frequently transacted, but they are actively managed against USD and affected by capital flow restrictions.

${ }^{13}$ The net debt component of NIIP comprises both portfolio debt as well as other debt investment. The net FDI component of NIIP comprises both debt and equity FDI. FDI indicates larger investments in which the direct investor owns at least $10 \%$ of the voting power in the direct investment enterprise.

${ }^{14}$ Campbell et al. (2010) shows that the risk-minimizing currency strategy for a global bond investor is close to a full currency hedge, while the currency risk is attractive for global equity investors
} 
after adjusting for interest rate differential. We also analyze the relative pricing of call and put options as additional evidence that corroborates the hedging channel. As we have shown in the model, cross-currency bases serve as important gauges of both hedging demand as well as the limits to arbitrage brought on by intermediary constraints. The direction and magnitude of the basis spreads in levels and in conditional movements reflect valuable information for identifying the source of the demand shock as well as whether the shock is first and foremost impounding the forward or the spot market.

Consistent with existing literature, we use Libor-based cross-currency basis swap levels as our empirical measure ${ }^{15}$. This basis spread is also commonly referred to as the deviations from covered interest rate parity condition, defined as the difference between the forward premium and interest rate differential:

$$
b_{t} \approx\left(f_{t, t+1}-s_{t}\right)+\left(r_{D, t}-r_{n, t}\right),
$$

where $r_{D, t}$ and $r_{n, t}$ are the Libor interest rates in the U.S. and foreign country $n$, respectively. $f_{t, t+1}$ and $s_{t}$ are the forward and spot (log) exchange rates quoted in terms of foreign currency per dollar. As defined here and equivalently in equation (3) in levels, foreign currency appreciation in the forward market represented by results in a negative cross-currency basis $b_{t}$ holding other terms fixed. We focus on Libor rates and forward rates at the one-year maturity, since forwards with maturities of less than one year are often affected by temporary spikes near quarter-ends and year-ends due to banks' regulatory window dressing (Du et al., 2018). Using alternative risk-free rates, such as overnight index swap rates and government bond yields, does not meaningfully affect our results, as presented in the Internet Appendix. Table 2 provides summary statistics for each of the variables used in our analysis.

\footnotetext{
${ }^{15}$ All market data are from Bloomberg.
} 


\section{Unconditional currency basis and external imbalances}

In this section, we present evidence for Proposition 1 in our model that relates currency basis and external imbalance. Fig. 3 shows the time series of cross-currency bases for G10 currencies since 2000. For clarity, a negative basis indicates the currency's forward price is overvalued relative to its spot price after adjusting for the interest rate differentials. A positive basis equates to an undervaluation of the currency in forward markets relative to the spot price.

Fig. 4 shows the average cross-sectional relationship between cross-currency basis spreads and external imbalances before and after the Global Financial Crisis (GFC) in 2008. The inverse relationship between external imbalance and currency basis attests to proposition 1 in our model. The larger the net international investment position, the more that the domestic currency is overvalued in the forward market relative to the spot market. The unconditional averages indicate a persistent hedging demand in which countries with large net foreign asset holdings buy domestic currency forwards as a hedge. Moreover, the inverse relationship between cross-currency bases and external imbalances appear even stronger when plotted against net debt and FDI, which is likely a stronger indicator of hedging demand.

Comparing the post-GFC sample (Fig. 4.A) with the pre-GFC sample (Fig. 4.B), the inverse relationship between external imbalances and currency bases holds true in both periods but the slope is steeper in the post-GFC period, indicating that the forward and the spot markets are more segmented from one another. In accordance with proposition 1, the steepening of the relationship since the GFC can reflect an increase in the hedging ratio $h$ or an increase in financial intermediary constraint $\kappa$. The latter channel focused on intermediary constraints has been discussed in prior studies. ${ }^{16}$ In addition to steepening of the unconditional relationship, the intercepts have also shifted lower from pre- to post- GFC. This likely reflects a general demand to sell dollar forwards associated with a worsening of

\footnotetext{
${ }^{16}$ For example, Basel III regulations raised balance sheet constraints of banks and affiliated broker dealers, see (Du et al., 2018; Adrian, Boyarchenko, and Shachar, 2017; Duffie, 2018) among others.
} 
the U.S. external imbalance - the U.S.'s NIIP had declined from an average of -18 percent of nominal GDP in the 2000 to 2007 period to an average of -33 percent of nominal GDP since 2008, though the current account deficit has slowed from -4.5 percent to -2.6 percent of nominal GDP.

Table 3 presents panel regressions of cross-currency basis spreads on external imbalances for the post-GFC sample. Consistent with Fig. 4, columns (1) through (4) confirm the strong inverse relationship between external imbalances between external imbalances and cross-currency bases. Columns (5) and (6) provide additional evidence that this inverse relationship is driven by the net debt and CPI components of NIIP rather than the net equity position.

\section{Exchange Rate Dynamics and External Imbalances}

In this section, we present empirical tests of proposition 2 and 3 from our model. Proposition 2 states that the conditional movements of currency basis spreads in the cross-section are predictable from external imbalances. Proposition 3 states that the conditional crosssectional returns of spot exchange rates are also influenced by the direction and magnitudes of external imbalances. We provide evidence for these propositions first through three case studies during the onset of the Covid-19 pandemic, the GFC, and the Eurozone Crisis. We then conclude with asset pricing factor tests that more formally analyze the relationship between external imbalances and exchange rates.

\subsection{COVID-19}

The market turmoil during the early onset of the Covid-19 pandemic was sharp and unexpected, thus providing an ideal test of our model predictions. Fig. 5 shows the level of 
currency bases (Panel A) and cumulative returns in spot exchange rates (Panel B) from February 1, 2020 to March 13, 2020. ${ }^{17}$

The time series show the largest market movements occurred starting in late February. The cross-sectional dispersion in currency bases and log spot returns are generally consistent with the external imbalance relationship as predicted by propositions 2 and 3. Panel A shows that while some currencies (e.g. Japanese yen) had bases that became sharply more negative (indicating relative overvaluation of the forward relative to the spot), other currencies (Australian and New Zealand dollars) had bases that became increasingly positive (indicating depressed forward relative to spot). Panel B shows the spot exchange rate changes during this period generally mirrored the movements in the currency basis. Yen spot exchange rates appreciated the most, and at the same time, yen had the most overvalued forward relative to spot (negative basis). The Australian dollar depreciated the second-most while experiencing the most positive currency basis, indicating that it had the most undervalued forward price relative to spot price. The one notable exception is the Norwegian Krone, which suffered the largest spot price decline among all G10 currencies but had little change in its currency basis. A likely explanation for the Krone's depreciation is that Norway's economy crucially depends on oil exports and the Brent Crude price declined from around $\$ 60$ to $\$ 20$ in this period.

In Fig 6, we show the changes in currency bases (Panel A) and log spot exchange rates (Panel B) plotted against measures of external imbalances. As we theorized, countries with large positive net foreign investments experienced more negative changes in their crosscurrency basis, indicating additional overvaluation in forward relative to spot. At the same time these countries with large positive net foreign investment positions experienced domestic

\footnotetext{
${ }^{17}$ We end the sample on March 13 because it was the Friday before the Federal Reserve's surprise Sunday announcement of a 100 basis point cut to the Fed Funds rate, and of extensions on central bank swap lines. However, our results are qualitatively similar using a different cutoff date. Various policy measures announced by different central banks in the ensuing weeks influenced exchange rates in channels beyond our model.
} 
currency appreciation. In contrast, countries with large external borrowings experienced the opposite dynamics.

\subsubsection{Central bank dollar liquidity swap line usage during COVID-19}

As discussed earlier, the offering of central bank swap lines not only reduces constraints for financial intermediaries (reducing $\kappa$ ) but also offers a release valve that temporarily reduces external imbalance $X_{D}$. In the case of the the dollar liquidity swap line offered by the Federal Reserve, the Fed entered agreements to sell dollar in the spot market and simultaneously purchase dollars in the forward market with foreign central bank counter-parties that then on lend the dollar liquidity to local institutions. As such, countries with the most demand for buying local currency forwards versus selling dollar forward stand to draw the most from the dollar liquidity facility. In our model, the demand for forwards emanates from the hedging of external imbalances translates into a prediction that the countries with the large net positive external assets also are the ones that draw the most from the dollar swap lines.

Fig. 7 illustrates this logic by showing the positive relationship between the maximum swap draws outstanding during the weeks following the Fed's swap line expansions, and the the associated countries' external imbalances in absolute dollar amounts (rather than as a percentage of GDP as examined above). Countries with low or negative NIIP and CA had little or no use of the dollar swap line, while countries with higher NIIP and CA had larger draws in absolute amount of dollar swap line.

\subsection{Global Financial Crisis and Eurozone Crisis}

We corroborate our evidence from the Covid-19 crisis by analyzing exchange rate movements during two additional periods of market turmoil: the Global Financial Crisis and the Eurozone Crisis. Fig. 8 captures changes in currency bases and log exchange rates during the GFC. ${ }^{18}$ Consistent with propositions 2 and 3, as well as the evidence from the Covid-19

\footnotetext{
${ }^{18}$ Our GFC sample captures the period September 1, 2008 from to October 1, 2008 when the currency bases peaked locally.
} 
crisis, currencies with more positive external imbalances generally observed larger decreases in their cross-currency bases. Currencies with more positive external imbalances also experienced domestic currency appreciation. Finally, Fig. 9 shows forward and spot exchange rate dynamics during the Eurzone crisis were also broadly consistent with propositions 2 and $3 .{ }^{19}$

\subsection{Cross-sectional Asset Pricing Tests}

We turn next to cross-sectional asset pricing tests. The purpose of these tests are to formally assess the following two hypotheses: (1) A country's external imbalance explains its currency's differential exposure to hedging demands and intermediary constraints, and (2) A country's exposure to hedging demand and intermediary constraints explains variation in forward and spot exchange rates over time. In other words, we assess whether the dynamics in forward and spot exchange rates observed in the Figures 6, 8 and 9 exist more generally. To perform these tests, we use monthly averages of currency bases and spot exchange rates for each of the currencies in our sample from January 2008 to April 2020.

First, we construct a risk factor intended to capture changes in hedging demand and intermediary balance sheet costs:

$$
\overline{\Delta|b|}_{t}=\frac{1}{N} \sum_{i=1}\left|b_{i, t}\right|-\left|b_{i, t-1}\right| .
$$

$\overline{\Delta|b|}_{t}$ is the average change in the magnitude of currency bases in the sample. Increases in $\overline{\Delta|b|}_{t}$ signal greater hedging demand or increases in the costs of financial intermediation. Proposition 2 shows countries with more positive external imbalances observe larger decreases in their currency bases when either hedging demand or the costs of financial intermediation increase. Hence, the currency basis of countries with more positive external imbalances should load more negatively on $\overline{\Delta|b|}$. Proposition 3 shows countries with more positive external imbalances appreciate more in response to increases in hedging demand. Hence,

\footnotetext{
${ }^{19}$ The Eurozone crisis sample captures the period from July 1, 2011 to August 11, 2011, when the currency bases peaked locally.
} 
changes in the log exchange rate of countries with more positive external balances should load more positively on the $\overline{\Delta|b|}_{t}$.

We run univariate regressions of the following form:

$$
\Delta y_{i, t}=\alpha_{i}+\beta_{i} \overline{\Delta|b|}_{t}+\varepsilon_{i, t}
$$

where $\Delta y_{i, t}$ captures changes in the variable of interest (i.e. the currency basis or the $\log$ spot exchange rate), and $\beta_{i}$ captures the loading of $\Delta y_{i, t}$ on the risk factor $\overline{\Delta|b|}_{t}$.

Fig. 10 plots $\beta_{i}$ against the country $i$ external imbalances. Panel A of Fig. 10 plots the betas of currency bases and shows there is a strong negative relation between the betas and the country's external imbalances. Consistent with proposition 2, countries with more positive external imbalances load more negatively on the mean average deviation. As the mean average deviation increases during times of financial distress, countries with more positive external imbalances observe their cross-currency bases become more negative and their forward exchange rates become more overvalued relative to the spot exchange rate.

Panel A of Table 5 presents the results of each univariate regression of changes in crosscurrency bases on changes in the mean absolute deviation. The currencies in Table 5 are ordered left-to-right from most negative average NIIP to most positive NIIP. These regression results confirm the negative relationship between $\beta_{i}$ and country $i$ 's external imbalance. Moreover, the $R^{2}$ from the univariate regressions tend to be high across the sample, suggesting this single factor model does a good job of explaining changes in currency basis over time for many of the currencies in our sample.

Panel B of Fig. 10 shows a strong negative relationship between currency returns and external imbalances. Consistent with proposition 3, countries with more positive external imbalances tend to appreciate more when the mean average deviation increases.

Panel B of Table 5 presents the results of each univariate regression of changes in spot exchange rates on changes in the mean absolute deviation. Naturally, the $R^{2} \mathrm{~s}$ in panel $\mathrm{B}$ 
of Table 5 tend to be lower relative to panel $\mathrm{A}$, indicating the single factor $\overline{\Delta|b|}_{t}$ explains a smaller share of the variation in exchange rates relative to the variation in currency bases. The smaller $R^{2}$ s are consistent with the notion that the demand for currencies in the spot market for hedging purposes are a smaller portion of all the demands for currencies in the spot market. Nevertheless, the average $R^{2}$ across the nine currencies is still 0.157.

Hence, we conclude our single factor model explains a significant portion of the variation in forward and spot exchange rates over our sample. Taken together, these results provide further evidence the hedging channel of exchange rate determination systematically explains dynamics of forward and spot exchange rate markets.

\subsection{Carry trade returns}

The conditional spot return and changes in cross-currency basis shown in the previous sections provide an explanation for the highly persistent differences in interest rates and currency returns across countries. A growing literature links differences in interest rates and currency returns across countries to the stochastic properties of currencies (Lustig and Verdelhan, 2007; Lustig, Roussanov, and Verdelhan, 2011). In particular, currencies that are likely to appreciate in periods of financial distress have lower unconditional returns, because they provide a hedge against states of the world in which marginal utility is high. Consistent with this literature, we highlight how time-varying currency hedging behaviors leads to predictable currency returns in both the time series and in the cross-section of countries.

Panel A of Fig. 11 shows the unconditional relationship between average currency excess returns and external imbalances. ${ }^{20}$ Countries with large positive external imbalances typically yield lower excess returns, and countries with large negative external imbalances yield higher returns. This result has been highlighted previously by DellaCorte et al. (2016) that attributes to a global imbalance risk factor in explaining this cross-sectional variation in currency excess returns. Our exchange rate hedging channel offers a mechanism to explain

\footnotetext{
${ }^{20}$ We calculate the log currency excess returns as: $r x_{t+1}=f_{t}-s_{t+1}=\left(f_{t}-s_{t}\right)-\left(s_{t+1}-s_{t}\right)$.
} 
why countries with positive external imbalances have currencies that appreciate in bad times and thus obtain unconditionally lower excess returns.

\subsection{Term structure of cross-currency basis}

The demand for hedging can also explain the term premia of cross-currency basis, as well as the returns from a forward-starting currency basis trade that has recently been described in Du et al. (2019). As we have shown in the conditional movements of cross-currency basis, countries with large negative imbalances have forwards that depreciate more than spot rates during a crisis (currency bases become more positive), whereas countries with positive imbalances have forwards that become more overvalued relative to spot rates (currency bases become more negative). In the theory section, Equation (9) showed the magnitude of longer maturity forwards (and cross-currency bases) should be larger in magnitude to compensate swap traders for the possibility of financial crises. In other words, longer maturity forwards embed a term premium and therefore the term structure of cross-currency is typically upward sloping in magnitude.

Fig. 12 illustrates the evolution of relative forward prices during the Covid-19 pandemic. One-month prior to the sudden market distress in March 2020, the term structure of cross-currency bases were indeed upward sloping in magnitude for the Australian dollar and Japanese yen. Longer maturity AUD forwards were more undervalued than shorter maturity forwards adjusting for interest rates with the respective maturities. In contrast, longer maturity JPY forwards were more over-valued than shorter maturity JPY forwards. During the ensuing period of market distress, the increased hedging demand led shorter maturity AUD forwards to depreciate, and JPY forwards to appreciate, as presented earlier in Figures 5 and 6 . Hence, the term structure of currency bases inverted during the crisis. This term structure inversion is intuitive as large short-term dislocations are expected to normalize over time. 
Next, we test for this systematic variation in the term structure of forward exchange rates more formally. First, Panel A of Fig. 13 confirms the unconditional term structure of crosscurrency bases is upwards sloping in magnitude. Countries with negative external imbalances (e.g. Australia) observe positive cross-currency bases term spreads indicating longer maturity forward exchange rates are more undervalued than shorter maturity forwards. Conversely, countries with positive external imbalances (e.g. Japan and Switzerland) observe negative term spreads indicating longer maturity forward exchange rates are more overvalued than shorter maturity forwards.

Panel B of Fig. 13 plots the betas of from regressions of changes in the slope of the cross-currency term bases on the mean average deviation of cross-currency bases. These betas show that during periods of financial distress the term structures of cross-currency bases systematically invert: The slopes of the term structures of countries with negative external imbalances become more negative, and the slopes of the term structure of countries with positive external imbalances become more positive. These results show the variation observed in AUD and JPY forward exchange rates in Fig. 12 are indicative of systematic variation in the term structure of forward exchange rates that is consistent with the hedging channel of exchange rate determination. ${ }^{21}$

\subsection{Hedged demand and options-pricing}

Currency hedging demand also has noticeable impact on the pricing of options on currencies. Out-of-the-money options have been used in prior studies to gauge rare disaster risk (Farhi and Gabaix, 2016; Barro and Liao, 2020) and currency crash risks (Farhi, Fraiberger, Gabaix, Ranciere, and Verdelhan, 2009; Chernov, Graveline, and Zviadadze, 2018; Jurek, 2014). Our

\footnotetext{
${ }^{21} \mathrm{Du}$ et al. (2019) documents a profitable trading strategy using forwards on cross-currency basis swaps to exploit the term premia. We show in Appendix B that these relationships also align with countries external imbalances. The conditional return profiles of these sophisticated trading strategies suggest that profits that were previously seen as alphas might in fact have been reflection of betas, as a phenomenon theorized in Cho (2020).
} 
hedging demand channel provides an explanation to the observed heterogeneity in the pricing of out-of-the-money calls and puts for different currencies.

The intuition is that investors in countries with net positive foreign investments can hedge against the appreciation of home currency (or equivalently the devaluation of their foreign currency position) by either buying forwards or purchasing calls on the domestic currency. Therefore, we would expect hedging demand to elevate (depreciate) both the price of forwards relative to spot and the price of calls relative to puts on the domestic currency when the external imbalance is positive (negative).

Consistent with this intuition, we find that countries with positive (negative) external imbalances have relatively more (less) expensive out-of-the-money call options compared to put options on their currency. This difference in the relative valuation between calls and puts also increases in times of heightened currency volatility. We use risk-reversals, defined as the implied volatility of the out-of-the-money call minus put, as a measure of the relative pricing of calls and puts for a given currency. ${ }^{22}$. Risk-reversals are routinely used by traders to assess the relative valuation of calls and puts and has been used in prior studies on currency options such as in Farhi and Gabaix (2016).

Fig. 14 shows the time series of risk reversals for the sample currencies. The graph highlights a few facts that resemble those of the currency basis as shown above in Fig. 3. First, options risk reversals increased in magnitude starting in 2008, a fact that has been highlighted in Farhi et al. (2009). In the context of our framework, this widening in the riskreversal is plausibly linked to the increase in hedging demand since 2008. Second, the figure shows substantial cross-sectional heterogeneity between currencies. Currency regions that has large negative external imbalances, e.g. Australia, typically have the most negative risk-

\footnotetext{
${ }^{22}$ Our primary measure is the one-year 25 -delta risk-reversal, defined as the implied volatility of on the call option with 25-delta minus the implied volatility of the put option with 25-delta, both of one-year maturity. The delta of the option is used in the currency market to denote an option's moneyness. A 25-delta option has option price that changes by one-quarter of a unit for every one unit change in the underlying currency price. 25-delta risk reversals is the most frequent indicator of option skewness used in practice. We also show similar results with 3 month maturity options in the appendix
} 
reversal, indicating a premium of put options over call options. ${ }^{23}$ Currencies with positive external imbalance or less negative external imbalance, e.g. Japan, have more expensive calls relative to puts, as indicated by positive risk reversals. This positive risk-reversal indicates more expensive hedging cost for currency appreciation rather than depreciation. Lastly, the risk-reversals widen in times of crisis in directions that are aligned with the hedging demand of external imbalances. This dispersion indicates that there is not a single dollar factor that dominate the dynamics of option skew.

Table 7 shows the panel regression of option risk-reversals on various measures of external imbalances. Similar to the previous results, the coefficients for Net Debt and FDI are the most significant. This signals that the hedging of fixed-income like investments are likely stronger than those of equities.

Fig. 15 presents the unconditional and conditional option risk-reversal levels relative to measures of external imbalances. The option risk-reveral results are consistent with the prior pricing dynamics of forwards - call options are expensive for JPY just as forward exchange rate on JPY is overvalued relative to spot exchange rate after adjusting for interest rate differentials. The opposite is true for AUD. This similarity makes intuitive sense as options and forwards are both hedging instruments that are potentially substitutable. Taken together, the cross-sectional and across-time variations in currency option prices provide another piece of evidence in support of our hedging demand framework. Additionally, the results on currency options also provide a unique empirical assessment of the demand-based option pricing as postulated in Garleanu, Pedersen, and Poteshman (2008).

\section{Conclusion}

In this paper, we presented a novel hedging channel of exchange rate determination. Recent evidence shows the use of currency forwards and swaps to hedge exchange rate risk is a

\footnotetext{
${ }^{23}$ A negative risk-reversal also translates into a left-skewness in the option-implied asset return distribution, as it is typical with equity index options.
} 
common and growing phenomenon around the world. We argued that this hedging behavior generates predictable movements in both spot and forward exchange rate markets that are also intimately linked to countries' external balances. Using data from the G10 currencies, we found evidence in support of the hedging channel of exchange rate determination in both conditional and unconditional moments of spot and forward exchange rate markets. Moreover, we showed our hedging channel explains the stochastic properties of spot and forward exchange rates that result in observed systematic variation in currency excess returns, term premia and out-of-the-money options on currencies. 


\section{References}

Adrian, T., N. Boyarchenko, and O. Shachar (2017). Dealer balance sheets and bond liquidity provision. Journal of Monetary Economics 89(C), 92-109.

Avdjiev, S., W. Du, C. Koch, and H. S. Shin (2019). The dollar, bank leverage and the deviation from covered interest parity. American Economic Review: Insights 1, 193-208.

Bahaj, S. and R. Reis (2018). Central bank swap lines. Unpublished working paper. CEPR.

Barro, R. J. and G. Liao (2020). Rare disaster probability and options-pricing. Journal of Financial Economics.

Camanho, N., H. Hau, and H. Rey (2018). Global portfolio rebalancing and exchange rates. Technical report.

Campbell, J. Y., K. Serfaty-De Medeiros, and L. M. Viceira (2010). Global currency hedging. The Journal of Finance 65(1), 87-121.

Chernov, M., J. Graveline, and I. Zviadadze (2018). Crash risk in currency returns. Journal of Financial and Quantitative Analysis 53(1), 137-170.

Cho, T. (2020). Turning alphas into betas: Arbitrage and endogenous risk. Journal of Financial Economics.

DellaCorte, P., S. J. Riddiough, and L. Sarno (2016). Currency premia and global imbalances. Review of Financial Studies.

Du, W., B. Hebert, and A. W. Huber (2019). Are intermediary constraints priced? Technical report.

Du, W., J. Im, and J. Schreger (2018). The us treasury premium. Journal of International Economics 112, 167-181.

Du, W., A. Tepper, and A. Verdelhan (2018). Deviations from covered interest rate parity. Journal of Finance 73(3), 915-957.

Duffie, D. (2018). Financial regulatory reform after the crisis: An assessment. Management Science 64 (10), 4835-4857.

Engel, C. and S. P. Y. Wu (2019). Liquidity and exchange rates: An empirical investigation. Technical report.

Evans, M. D. and R. K. Lyons (2002). Order flow and exchange rate dynamics. Journal of Political Economy 110(1), 170-180.

Farhi, E., S. P. Fraiberger, X. Gabaix, R. Ranciere, and A. Verdelhan (2009). Crash risk in currency markets. 
Farhi, E. and X. Gabaix (2016). Rare disasters and exchange rates. Quarterly Journal of Economics 131(1), 1-52.

Froot, K. A. and T. Ramadorai (2005). Currency returns, intrinsic value, and institutional investor flows. Journal of Finance 60 (3), 1535-1566.

Gabaix, X. and M. Maggiori (2015). International liquidity and exchange rate dynamics. Quarterly Journal of Economics 130(3), 1369-1420.

Gârleanu, N. and L. H. Pedersen (2011). Margin-based asset pricing and deviations from the law of one price. Review of Financial Studies 24(6), 1980-2022.

Garleanu, N., L. H. Pedersen, and A. M. Poteshman (2008). Demand-based option pricing. The Review of Financial Studies 22(10), 4259-4299.

Goldberg, L. S., C. Kennedy, and J. Miu (2010). Central bank dollar swap lines and overseas dollar funding costs.

Gourinchas, P.-O. and H. Rey (2007). International financial adjustment. Journal of Political Economy 115(4), 665-703.

Greenwood, R., S. G. Hanson, J. C. Stein, and A. Sunderam (2019). A quantity-driven theory of term premiums and exchange rates. Technical report, Harvard University and NBER.

Greenwood, R. and D. Vayanos (2010). Price pressure in the government bond market. American Economic Review 100(2), 585-590.

Greenwood, R. M. and A. Vissing-Jorgensen (2018). The impact of pensions and insurance on global yield curves. Harvard Business School Finance Working Paper (18-109).

Hanson, S. (2014). Mortgage convexity. Journal of Financial Economics 113(2), 270-299.

Hassan, T. A. (2013). Country size, currency unions, and international asset returns. The Journal of Finance 68(6), 2269-2308.

Ivashina, V., D. S. Scharfstein, and J. C. Stein (2015). Dollar funding and the lending behavior of global banks. Quarterly Journal of Economics 1241, 1281.

Jiang, Z., A. Krishnamurthy, and H. Lustig (2019). Foreign safe asset demand and the dollar exchange rate.

Jurek, J. W. (2014). Crash-neutral currency carry trades. Journal of Financial Economics $113(3), 325-347$.

Klinger, S. and S. Sundaresan (2019). An explanation of negative swap spreads: Demand for duration from underfunded pension plans. The Journal of Finance 74 (2), 675-710.

Kremens, L. and I. Martin (2019). The quanto theory of exchange rates. American Economic Review $109(3)$, 810-843. 
Krishnamurthy, A. and A. Vissing-Jorgensen (2011). The effects of quantitative easing on interest rates: channels and implications for policy. National Bureau of Economic Research.

Levich, R. M., G. S. Hayt, and B. A. Ripston (1999). 1998 survey of derivatives and risk management practices by us institutional investors.

Liao, G. Y. (2019). Credit migration and covered interest rate parity. Journal of Financial Economics, forthcoming.

Lilley, A., M. Maggiori, B. Neiman, and J. Schreger (2019). Exchange rate reconnect. Technical report.

Lilley, A. and G. Rinaldi (2020). Currency betas and interest rate spreads. Technical report.

Lustig, H., N. Roussanov, and A. Verdelhan (2011). Common risk factors in currency markets. Review of Financial Studies 24 (11), 3731-3777.

Lustig, H. and A. Verdelhan (2007). The cross section of foreign currency risk premia and consumption growth risk. American Economic Review 97(1), 89-117.

Maggiori, M. (2017). Financial intermediation, international risk sharing, and reserve currencies. American Economic Review 107(10), 3038-71.

Meese, R. and K. Rogoff (1983). The out-of-sample failure of empirical exchange rate models: Sampling error or misspecification? In Exchange Rates and International Macroeconomics, NBER Chapters, pp. 67-112. National Bureau of Economic Research, Inc.

Richmond, R. (2019). Trade network centrality and the currency carry trade. The Journal of Finance 74(3), 1315-1361.

Shleifer, A. (1986). Do demand curves for stocks slope down? Journal of Finance 41(3), $579-590$.

Vayanos, D. and J.-L. Vila (2009). A preferred-habitat model of the term structure of interest rates. National Bureau of Economic Research.

Wiriadinata, U. (2020). External debt, currency risk, and international monetary transmission. Technical report, IMF. 


\section{$6 \quad$ Figures and Tables}

Figure 2: Global foreign exchange market turnover

This figure presents the daily average foreign exchange market turnover as presented in the Triennial Central Bank Survey of Foreign Exchange and Over-the-counter (OTC) Derivatives Markets in 2019 from Bank of International Settlements.

Panel A. Average daily volume by currency and instrument (2019):

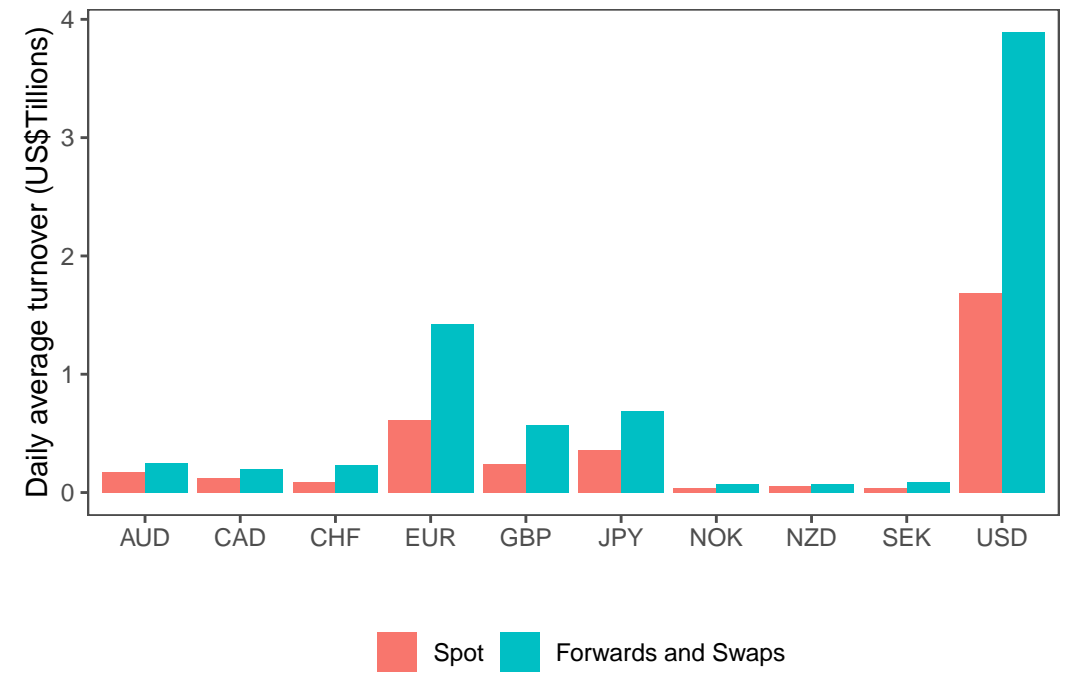

Panel B. Evolution of average daily volume by instrument:

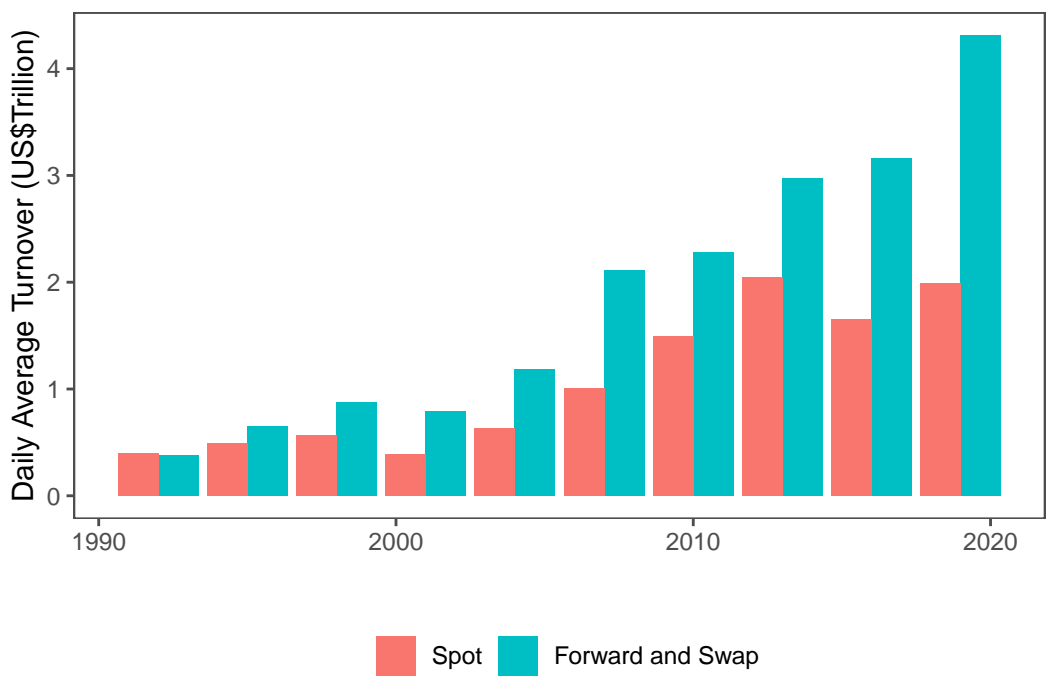


Figure 3: Cross-currency basis

This figure presents the deviations from covered interest rate parity relations based on crosscurrency basis swaps of 1 year maturity for G10 currencies. The sample period expands from January 2008 until April 2020.

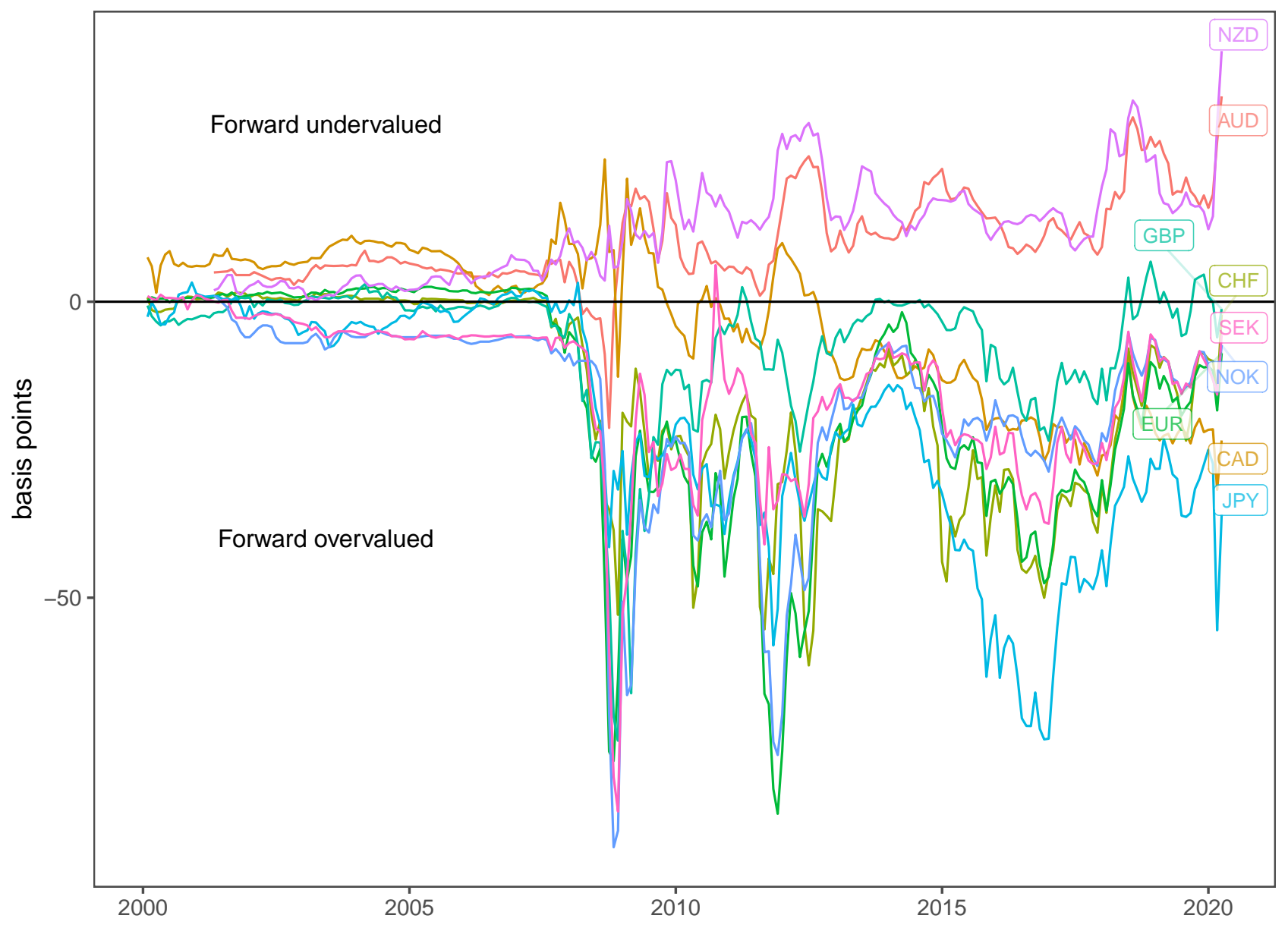


Figure 4: External imbalances and unconditional cross-currency bases

This figure presents the average relationship between cross-currency bases and external imbalances pre- and post- 2008. Panel A shows the post-crisis sample from January 2008 to December 2020. Panel B shows the pre-crisis sample from January 2000 to December 2007.

Panel A. Unconditional cross-currency Bases from 2008-2020:
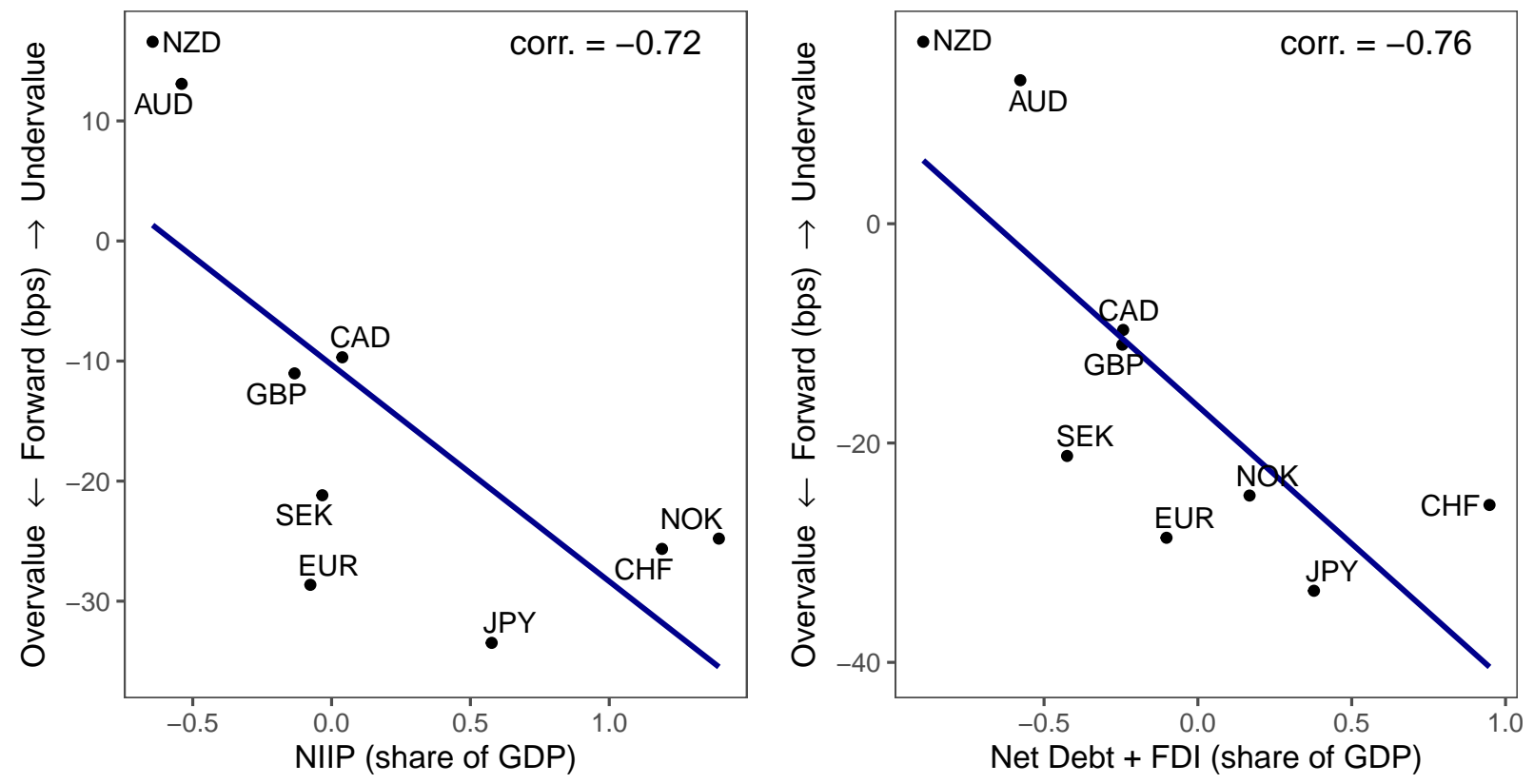

Panel B. Panel A. Unconditional cross-currency Bases from 2000-2007:
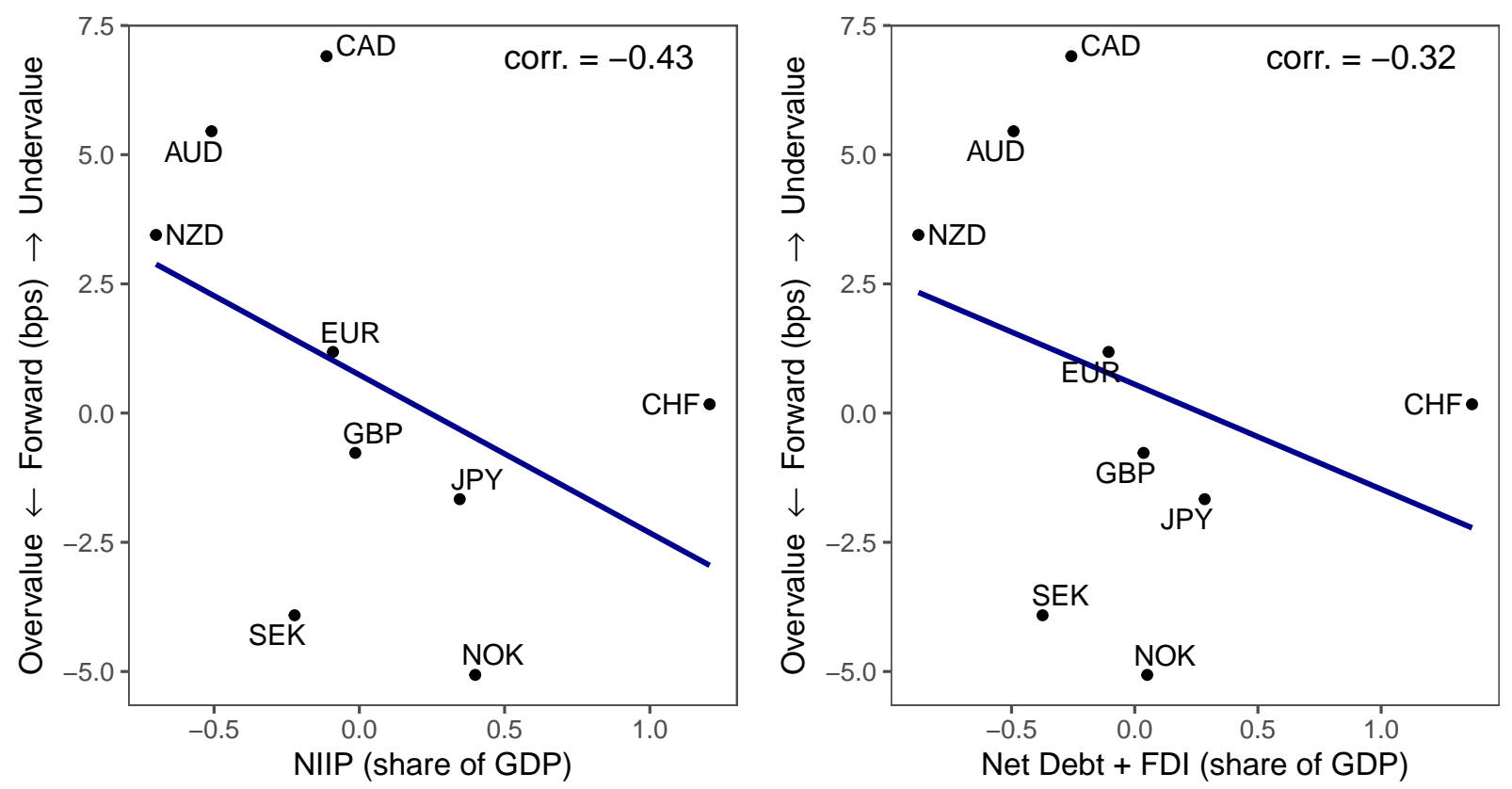
Figure 5: Cross-currency bases and spot exchange rates during COVID-19 crisis

This figure presents time series of cross-currency bases and spot exchange rates during the COVID-19 global pandemic. Panel A plots the time series of currency basis from February 1, 2020 to Friday March 13, 2020. We end the sample on March 13, 2020, the Friday before the Federal Reserve cut the federal funds rate by 100 basis points and extended central bank swap line provision on Sunday March 15, 2020. Panel B plots the times series of cumulative returns in log spot exchange rates from February 1, 2020 to March 13, 2020.

Panel A. Currency Bases

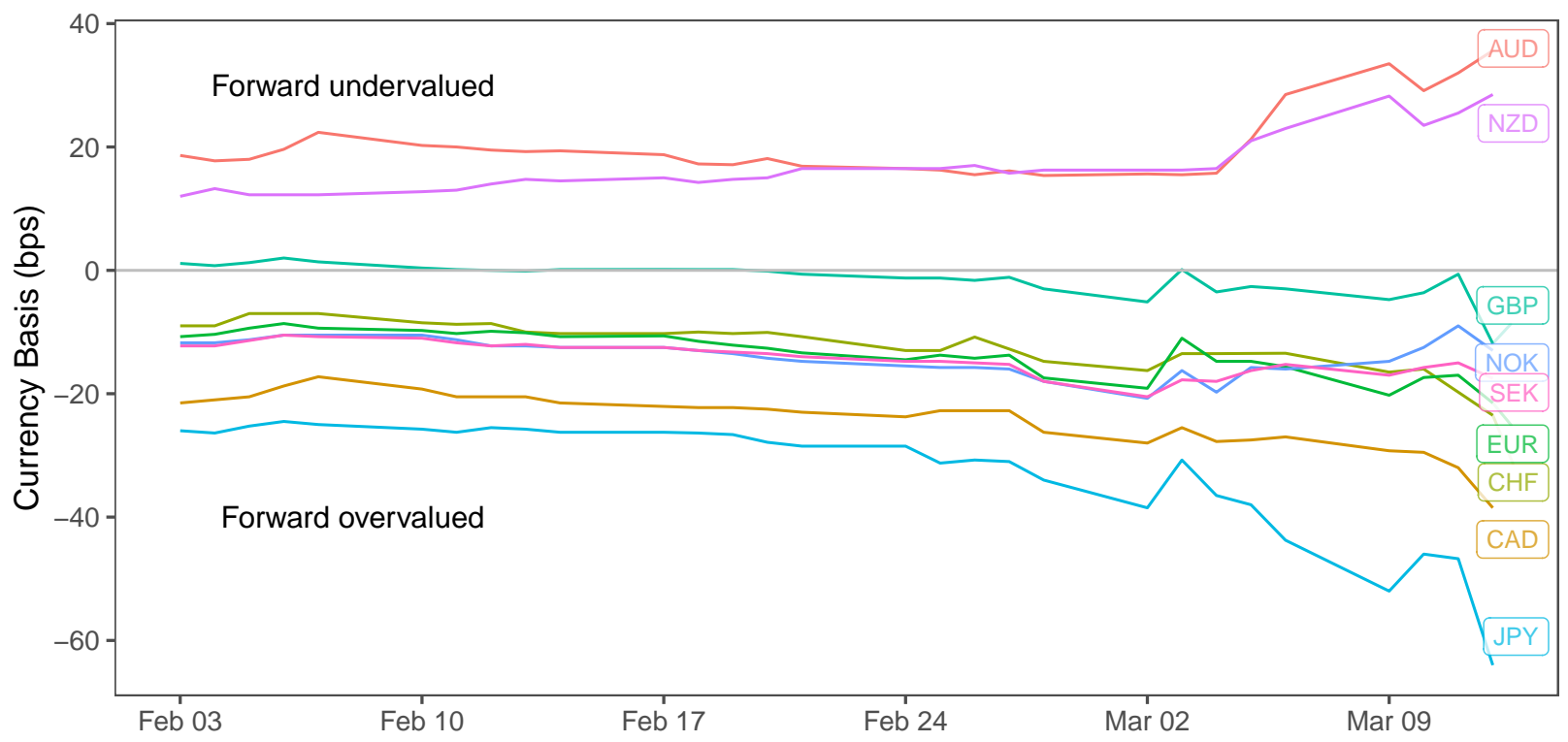

Panel B. Spot Exchange Rates (Cumulative Returns)

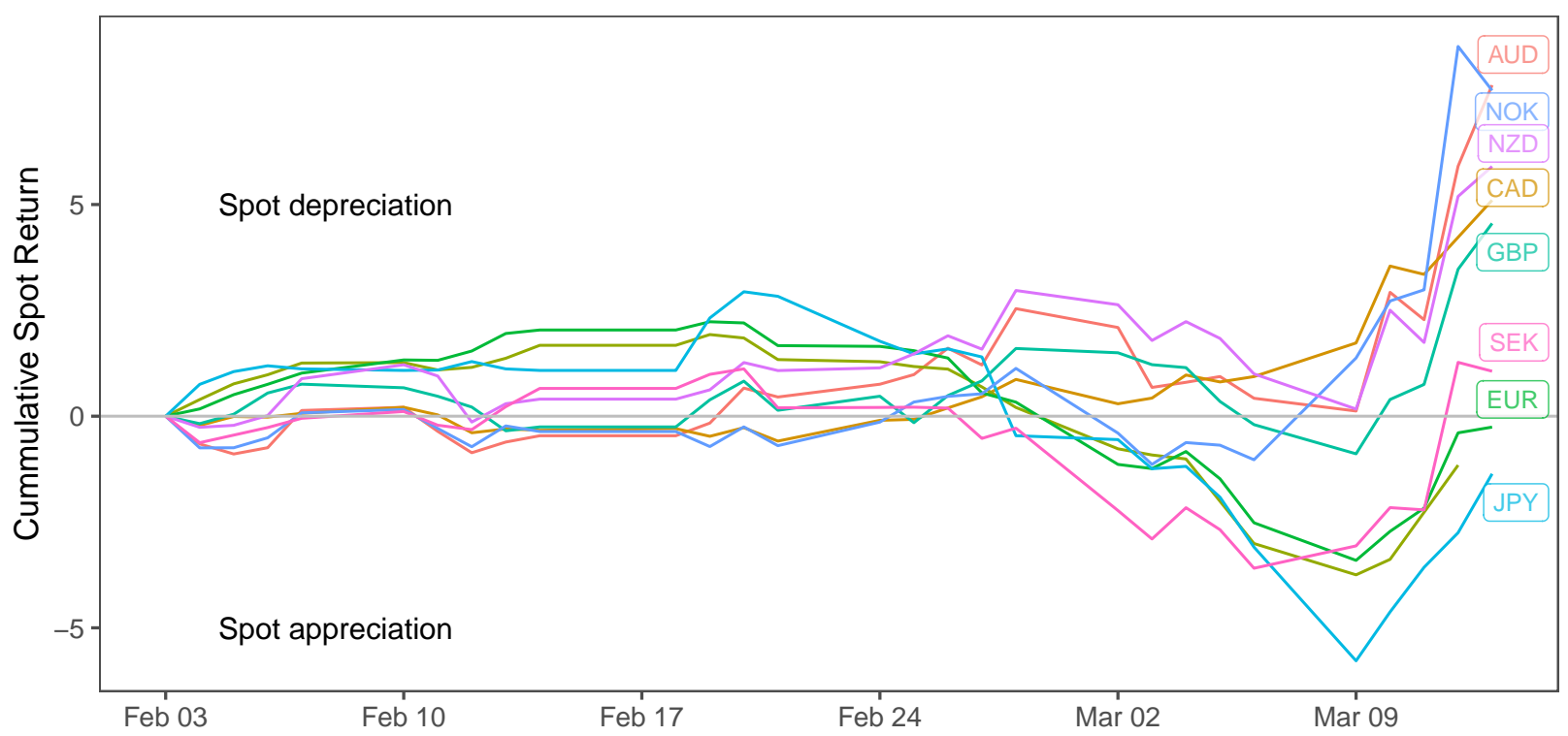


Figure 6: External imbalances and exchange rates during COVID-19 crisis

This figure plots changes in currency bases and spot exchange rates during the COVID-19 crisis. We measure changes in currency bases and exchange rates from February 1, 2020 to March 13, 2020, the Friday before the Federal reserve cut the federal funds rate by 100 basis points and extended central bank swap line provision on Sunday March 15, 2020. The Norwegian Krone is omitted when calculating the correlation and the regression line between log spot exchange rate returns and external imbalances.

Panel A. Changes in Currency Bases
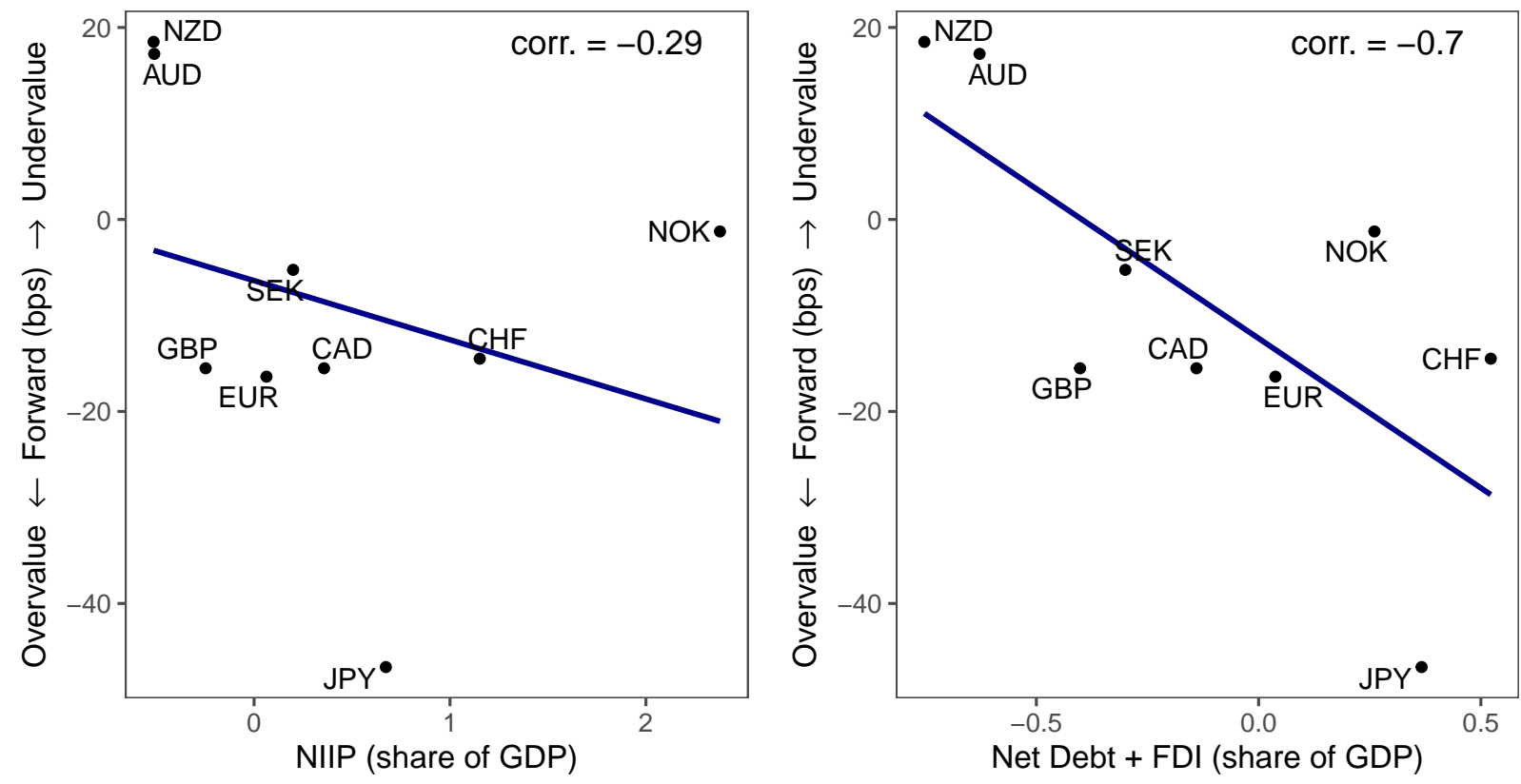

Panel B. Changes in Log Exchange Rates
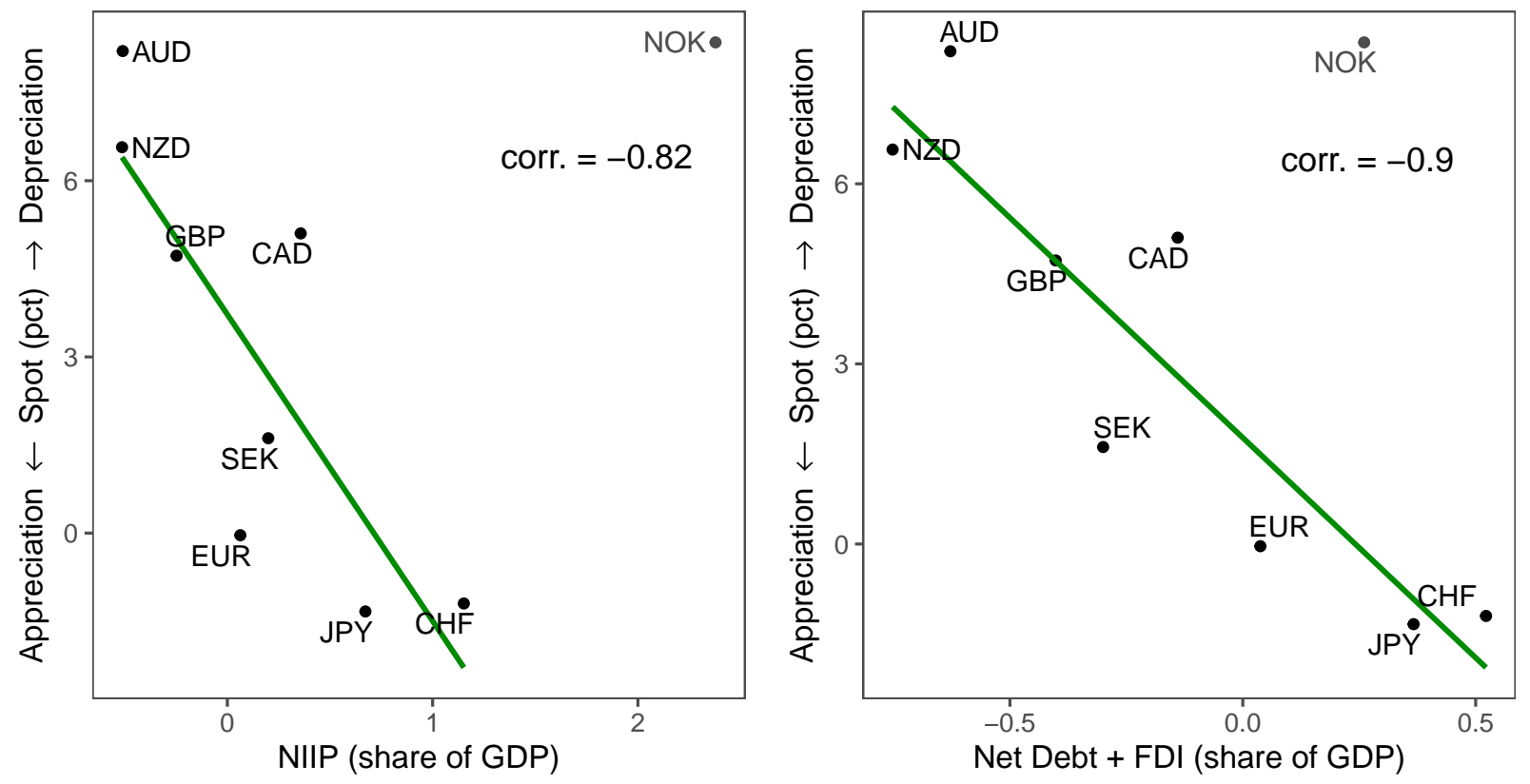
Figure 7: Central bank swap line usage during COVID-19 crisis

This figure plots maximum swap line draws by central banks during the Covid market turmoil against measures of external imbalances taken from the latest quarterly data available in 2019 .
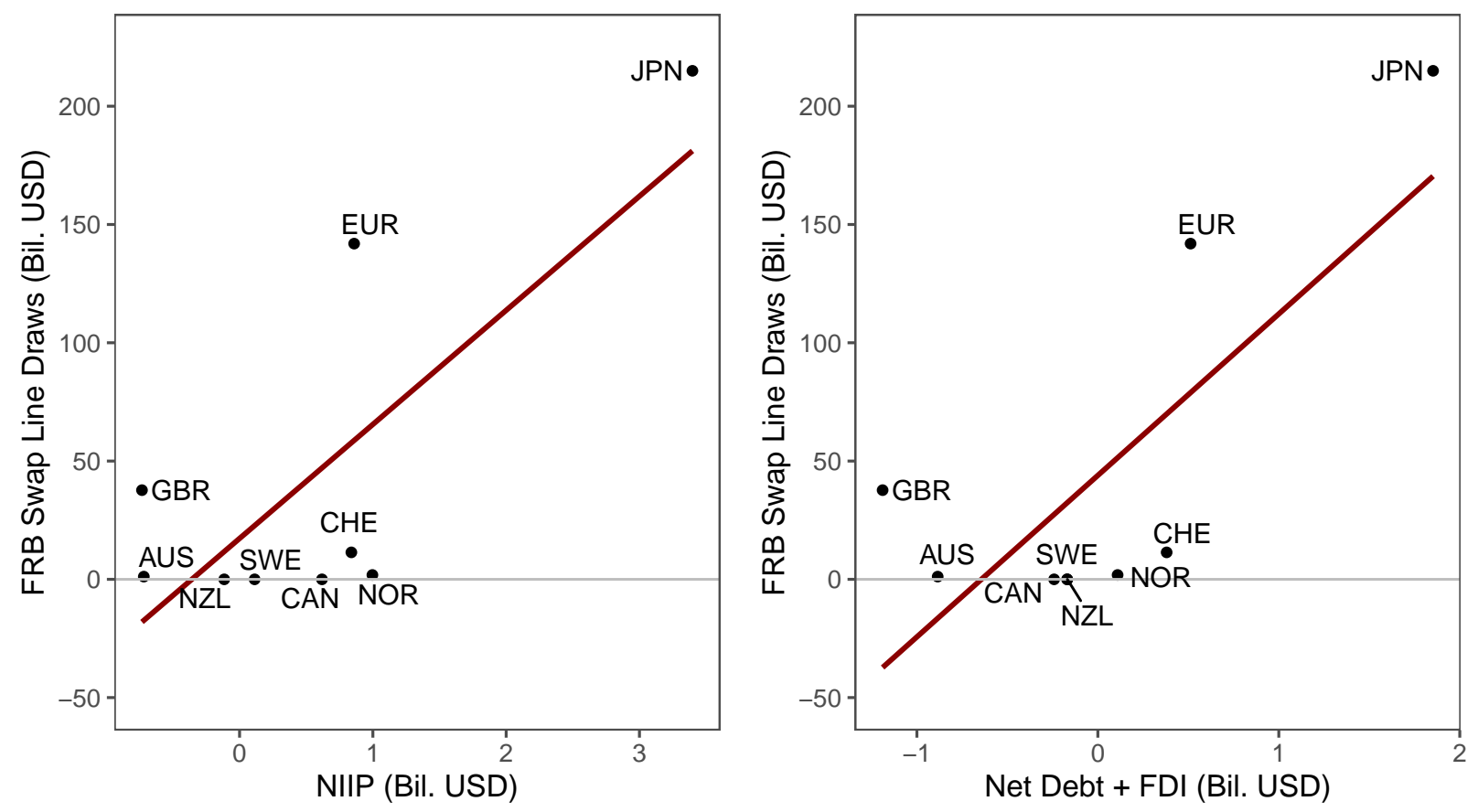
Figure 8: External imbalances and exchange rates during Global Financial Crisis This figure plots changes in currency bases and spot exchange rates during the Global Financial Crisis. We measure changes in currency bases and exchange rates from September 1, 2008 to October 1, 2008, when the magnitude of the bases peaked. We measure external imbalances in terms of countries' NIIP and current account at the end of 2007.

Panel A. Changes in Currency Bases
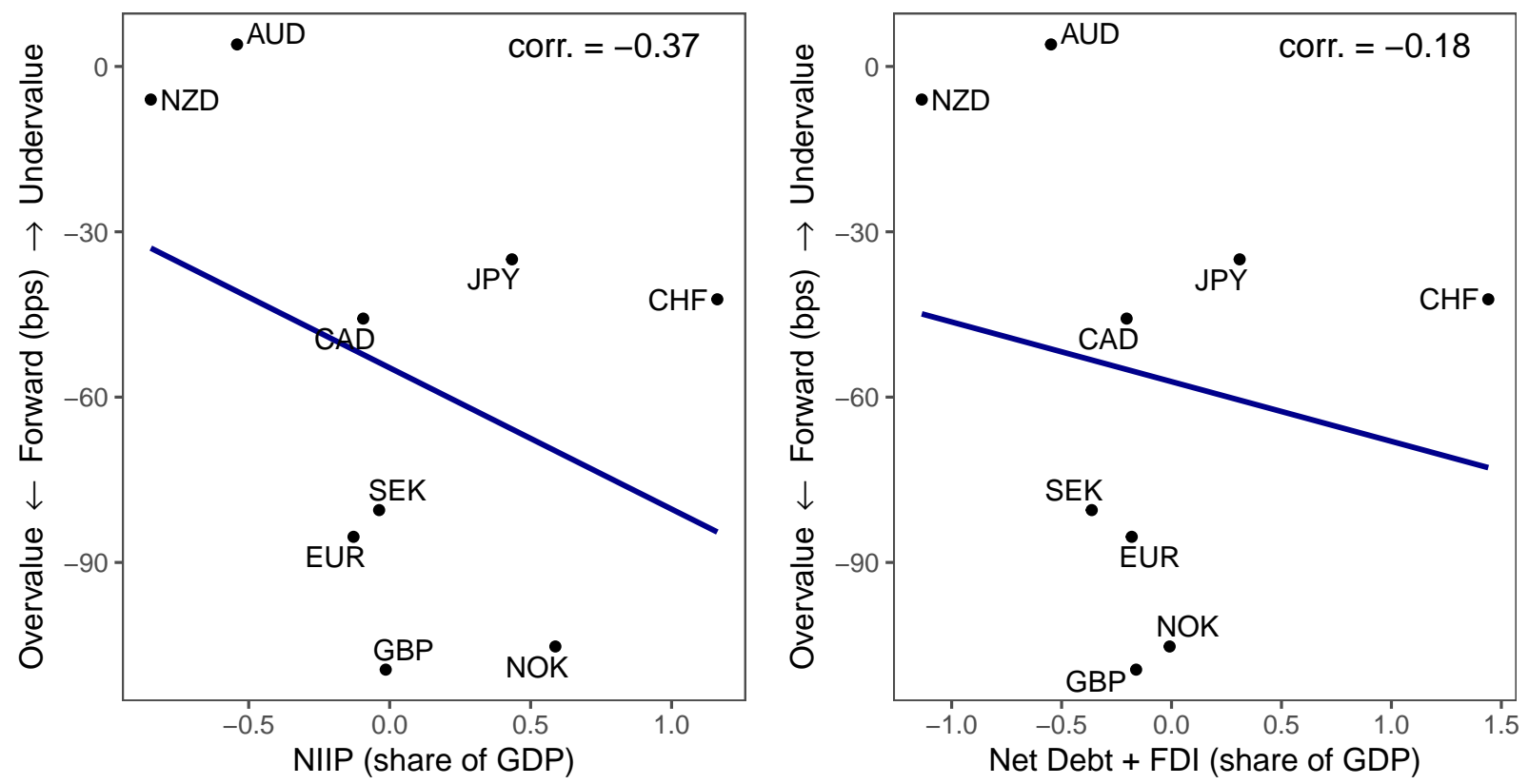

Panel B. Changes in Log Exchange Rates
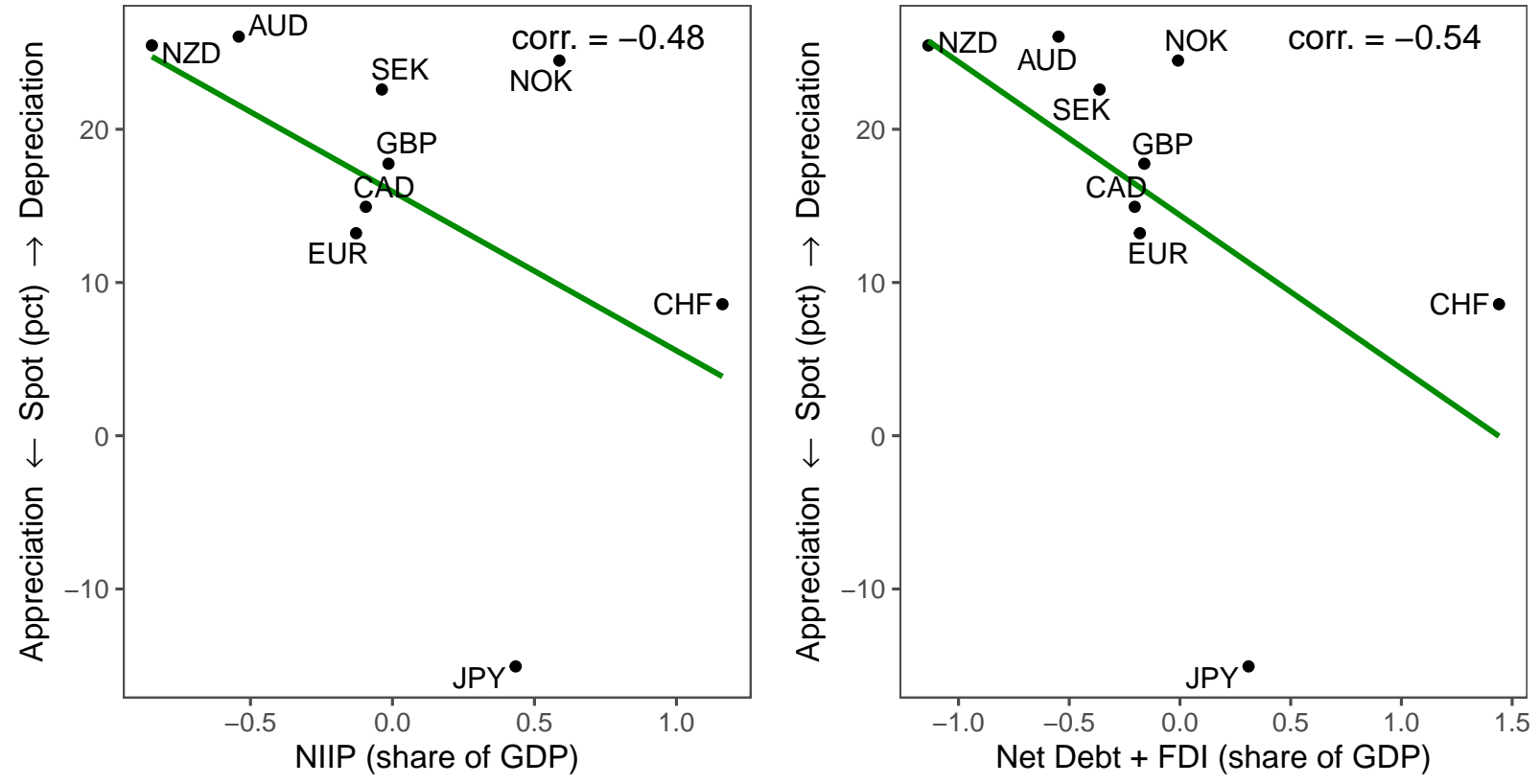
Figure 9: External imbalances and exchange rates during Eurozone crisis

This figure plots changes in currency bases and spot exchange rates during the Eurozone crisis. We measure changes in currency bases and exchange rates from July 1, 2011 to August 11, 2011. We measure external imbalances in terms of countries' NIIP and current account at the end of 2010 .

Panel A. Changes in Currency Bases
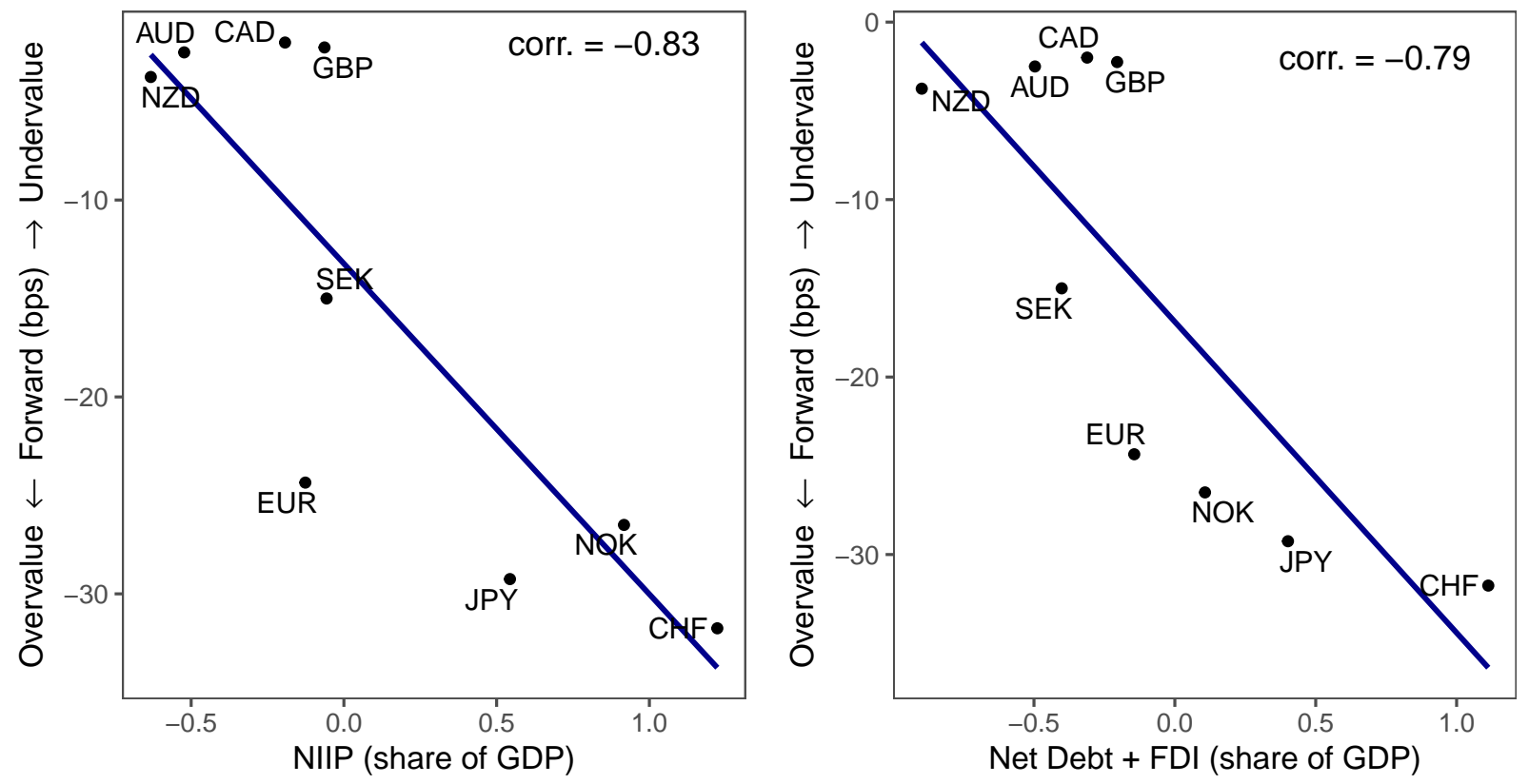

Panel B. Changes in Log Exchange Rates
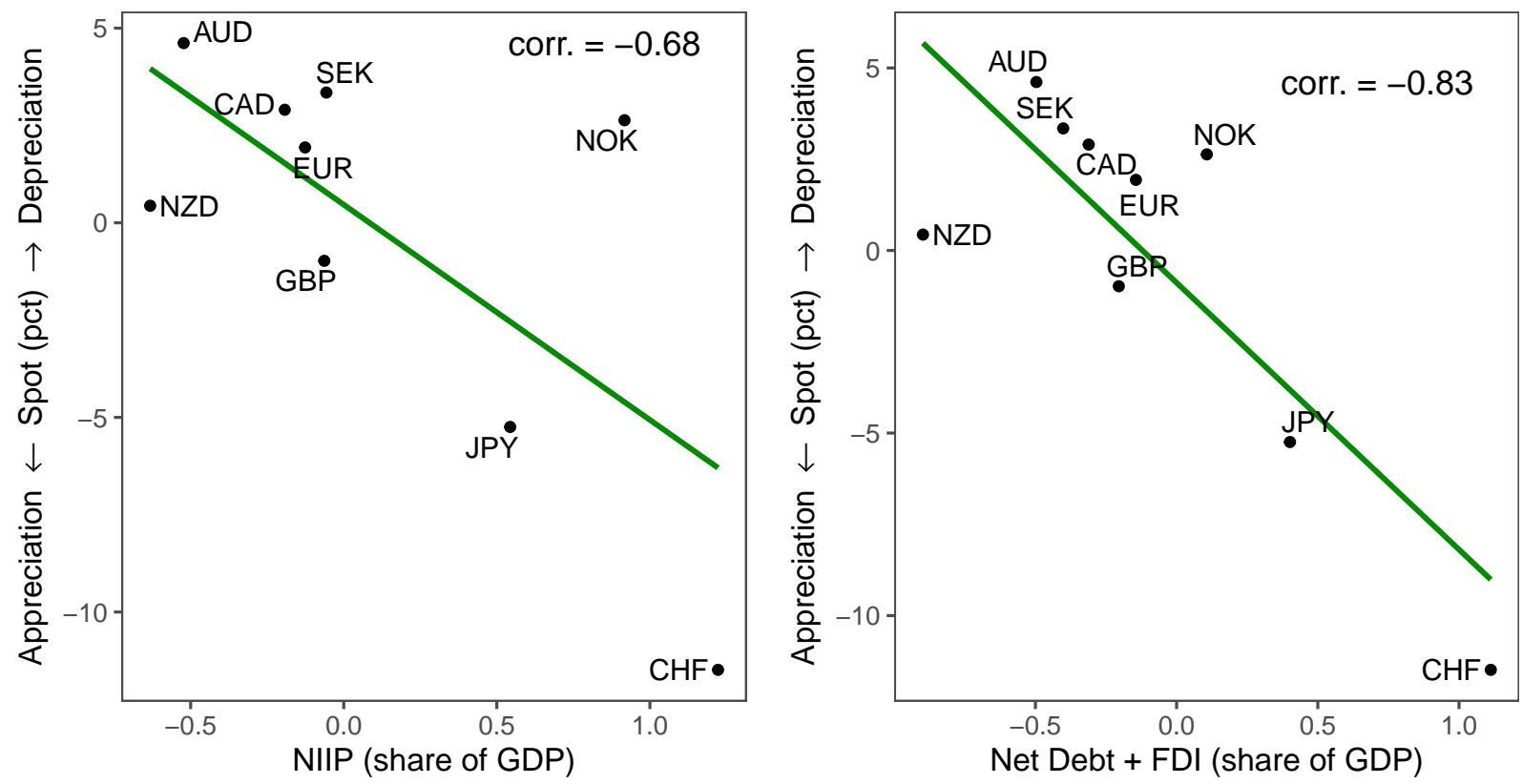
Figure 10: A single factor model of spot and forward exchange rates

This figure plots coefficients $\beta_{i}$ from estimating single-factor models of changes in crosscurrency bases, spot exchange rates and the cross-currency term spread against countries' external imbalances. We plot $\beta_{i}$ from the regression: $\Delta y_{i, t}=\alpha_{i}+\beta_{i} \overline{\Delta b}_{t}+\varepsilon_{i, t}$, where $\Delta y_{i, t}$ represents the outcome variable of interest for country $i$ at date $t$ and $\overline{\Delta b}_{t}=$ $(1 / N) \sum_{j=1}^{N}\left|b_{j, t}\right|-\left|b_{j, t-1}\right|$ is the mean absolute deviation (MAD) of countries' cross-currency bases.

Panel A. Factor loadings of changes in cross-currency bases
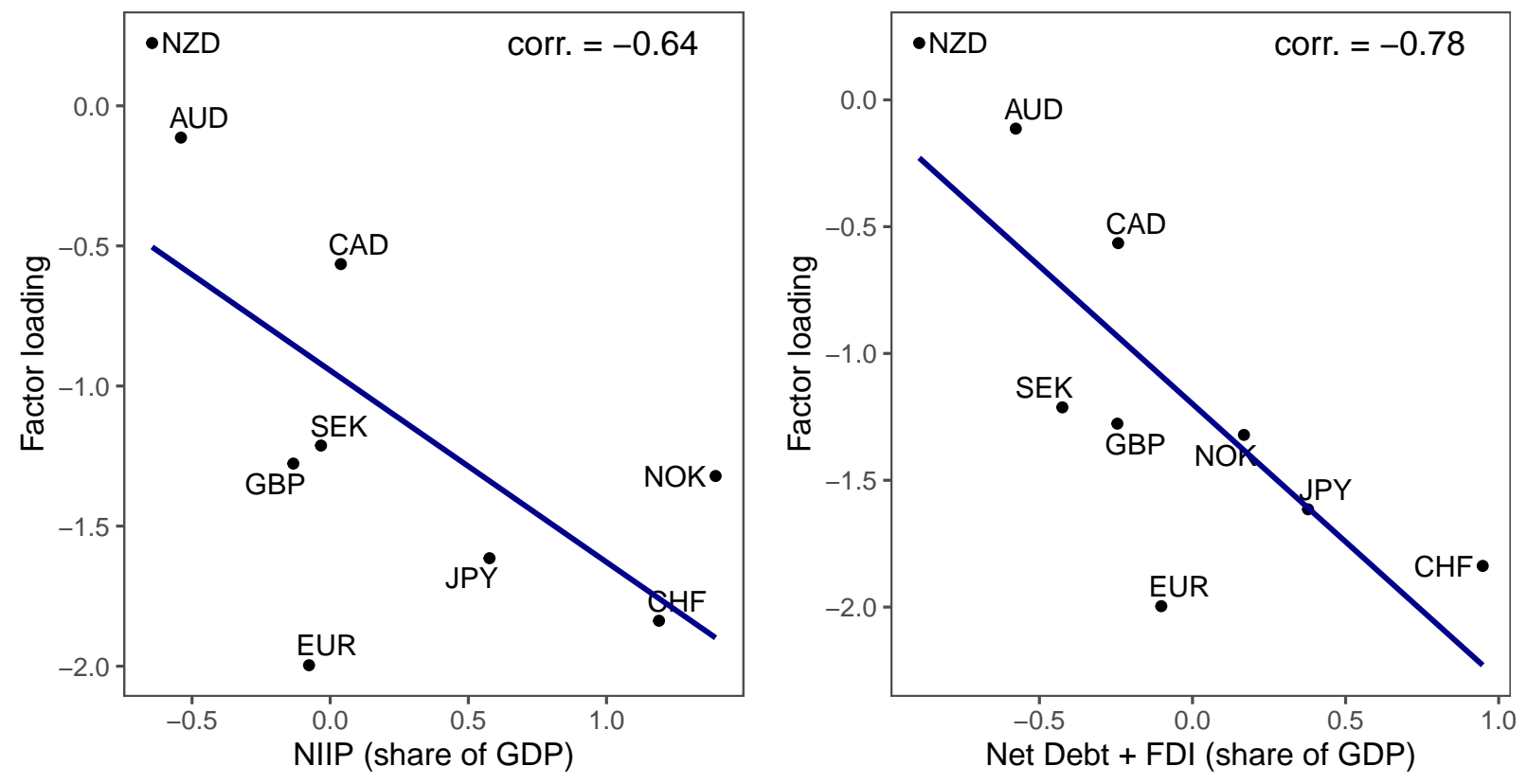

Panel B. Factor loadings of changes in spot exchange rates
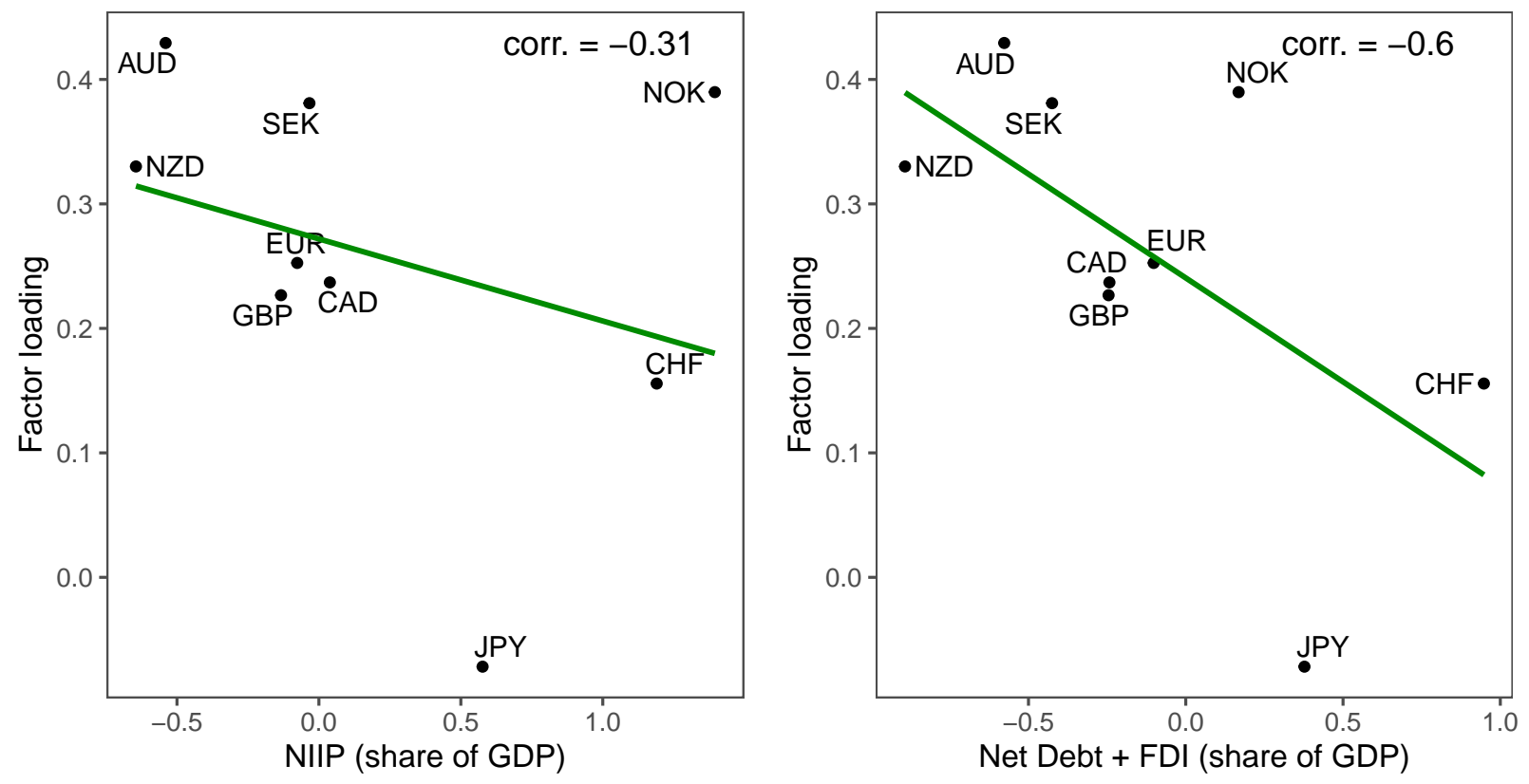
Figure 11: External imbalances and unconditional spot returns

Panel A plots average currency excess returns against measures of external imbalances. Panel B plots average forward premia against external imbalances. The sample comprises monthly observations of 1-year returns of G-10 currencies from January 2000 to April 2020.

Panel A. Average currency excess returns:
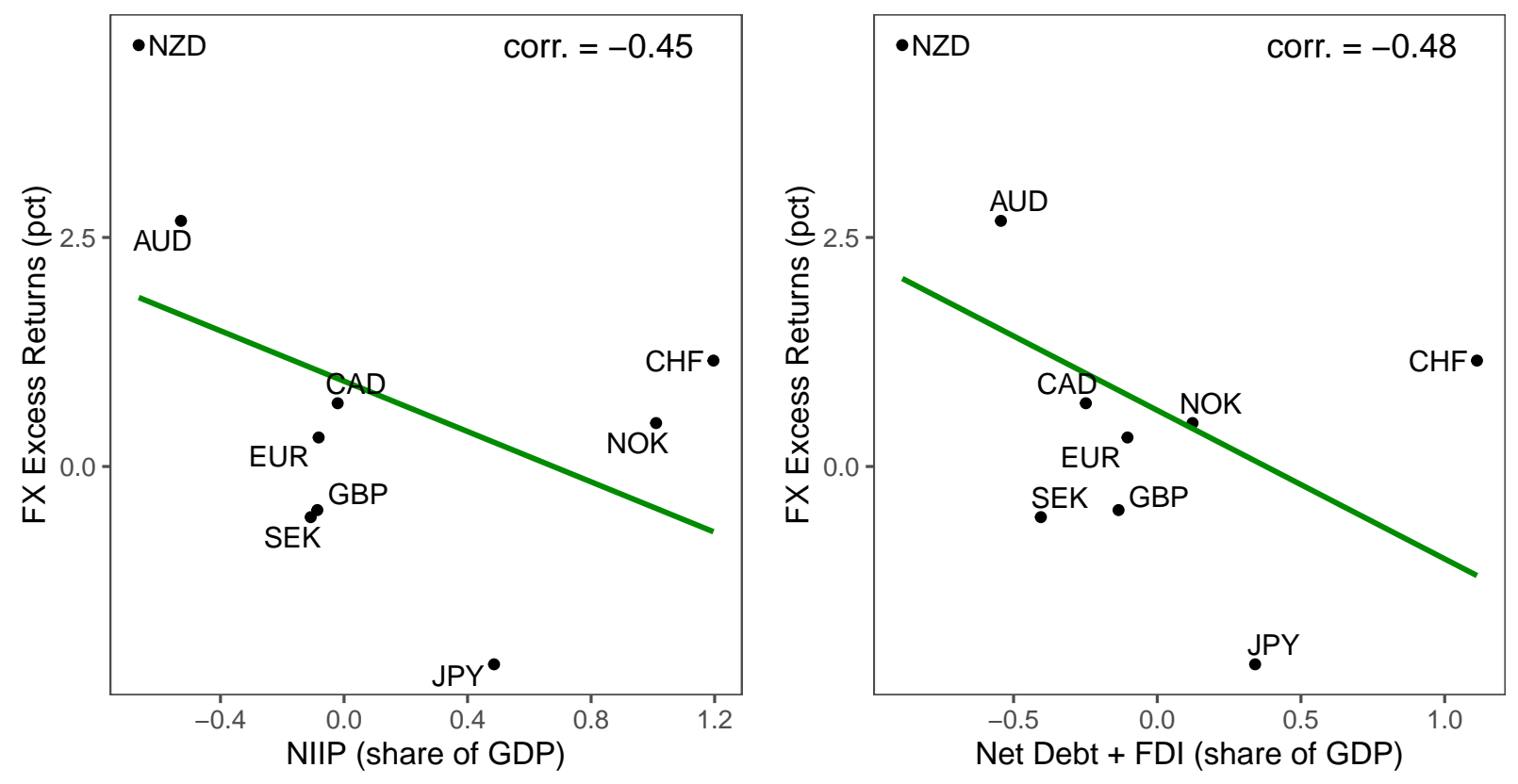

Panel B. Average forward premia:
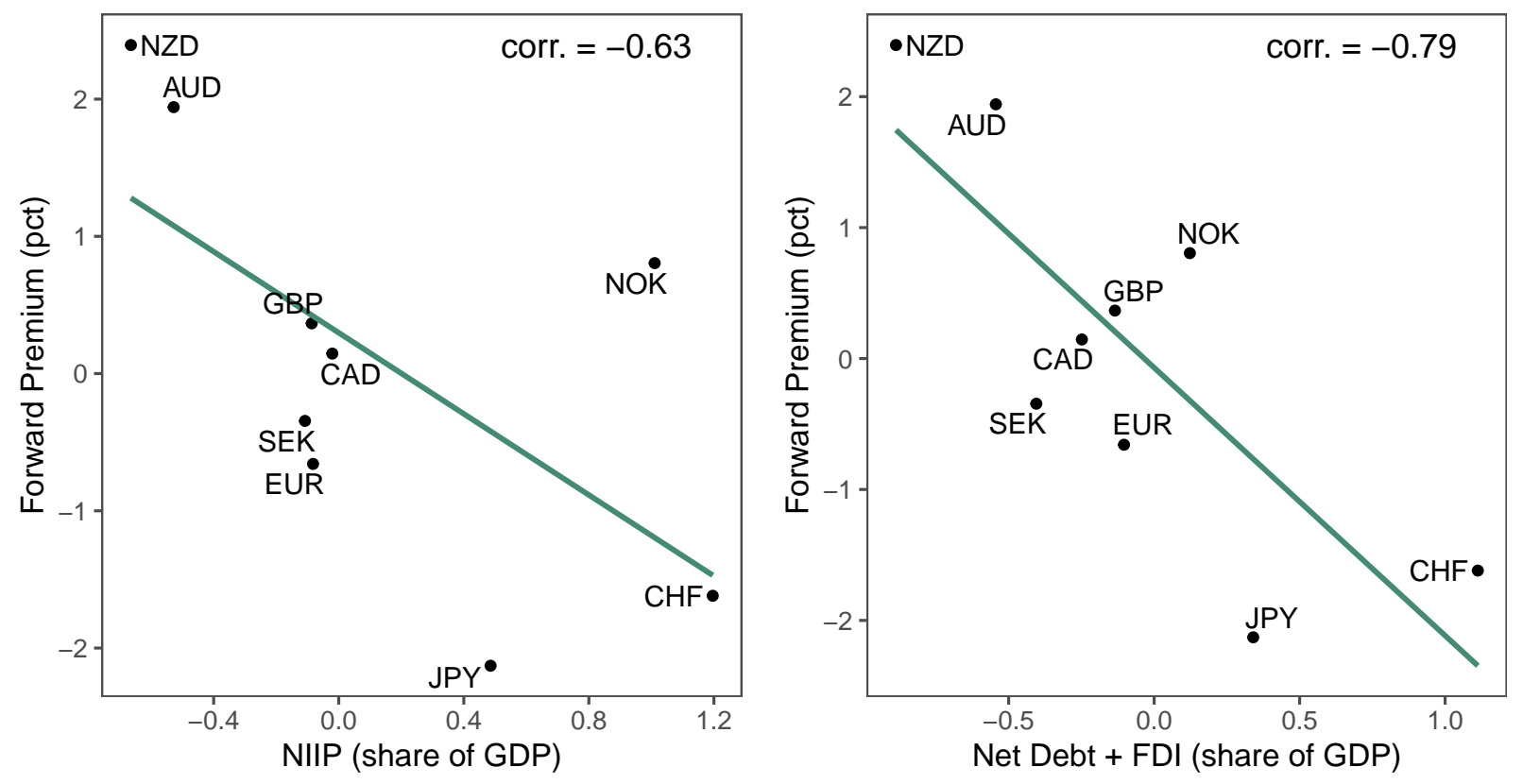
Figure 12: Term structure of cross-currency basis during COVID-19 crisis This figure presents the term structure of cross-currency basis for the Australian Dollar and the Japanese Yen on two dates around the COVID-19 pandemic.

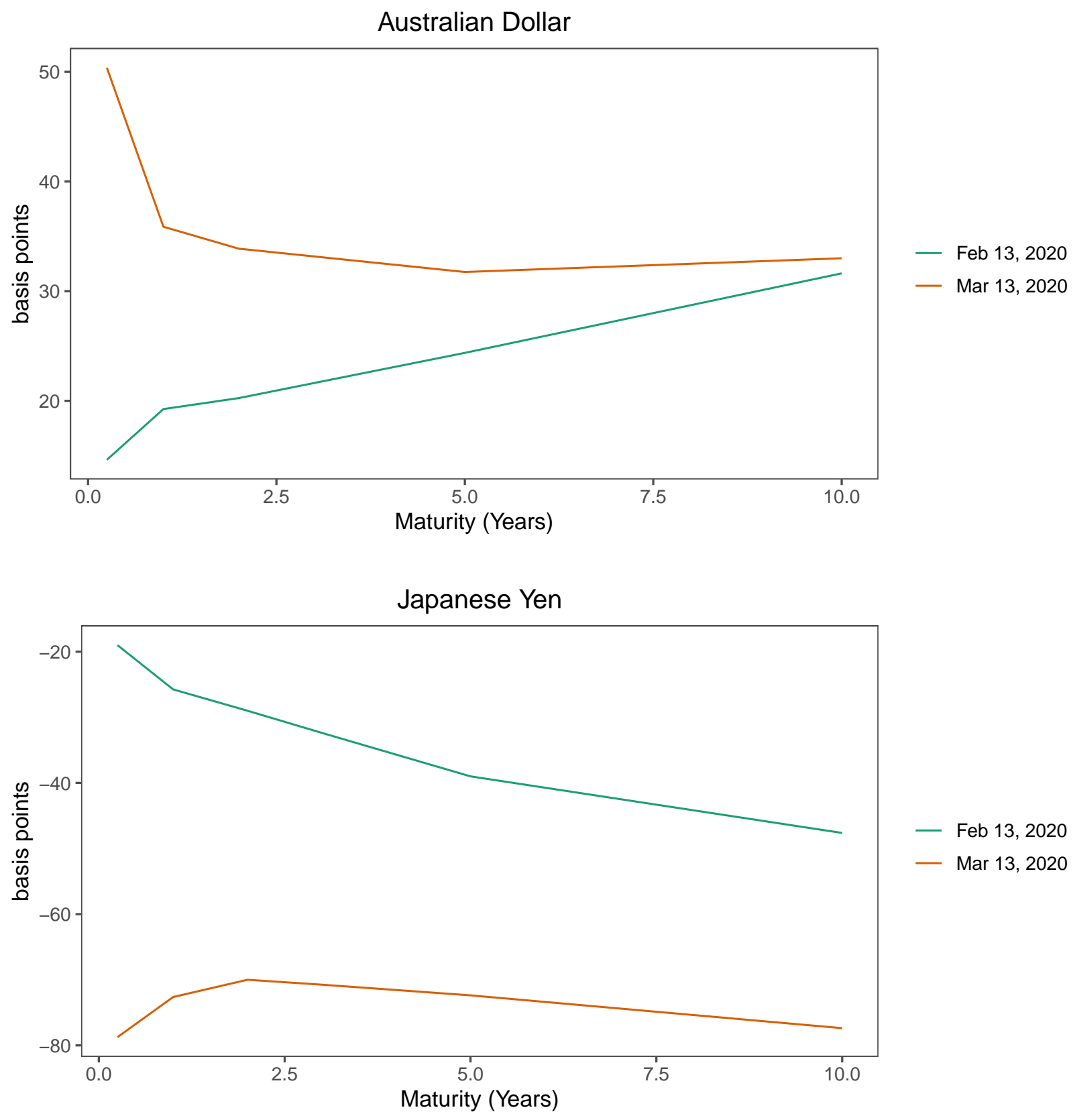


Figure 13: Conditional and unconditional exchange rate forward term structure

Panel A presents the term structure of cross-currency basis relative to countries' external imbalances. We plot the average unconditional 5-year minus 1-year cross-currency basis spread from January 2008 to April 2020. Panel B plots coefficients $\beta_{i}$ from estimating single-factor models of changes in the slope of cross-currency bases term structures against countries' external imbalances.

Panel A. Unconditional 5-year minus 1-year bases spread
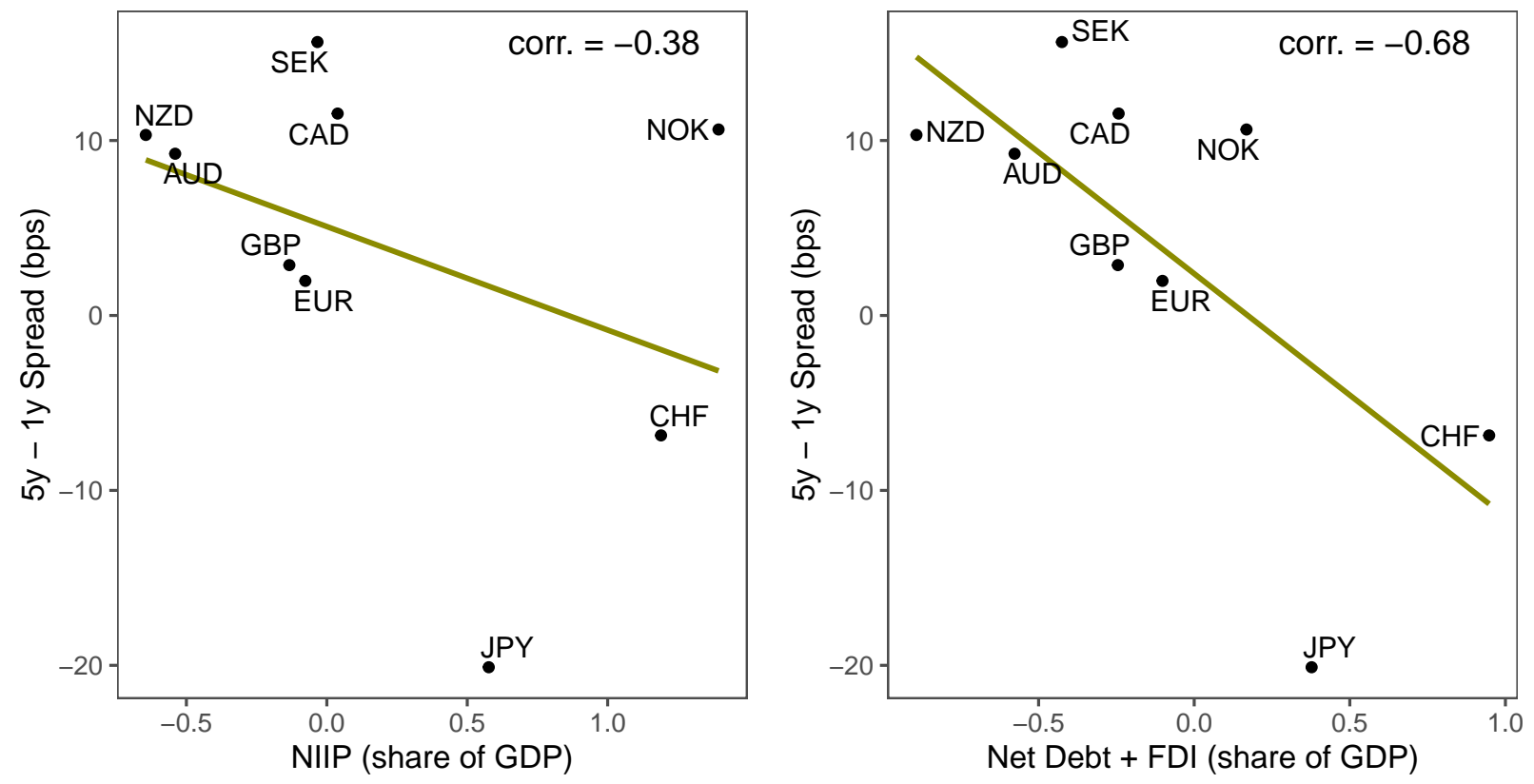

Panel B. Factor loadings of 5-year minus 1-year bases spread
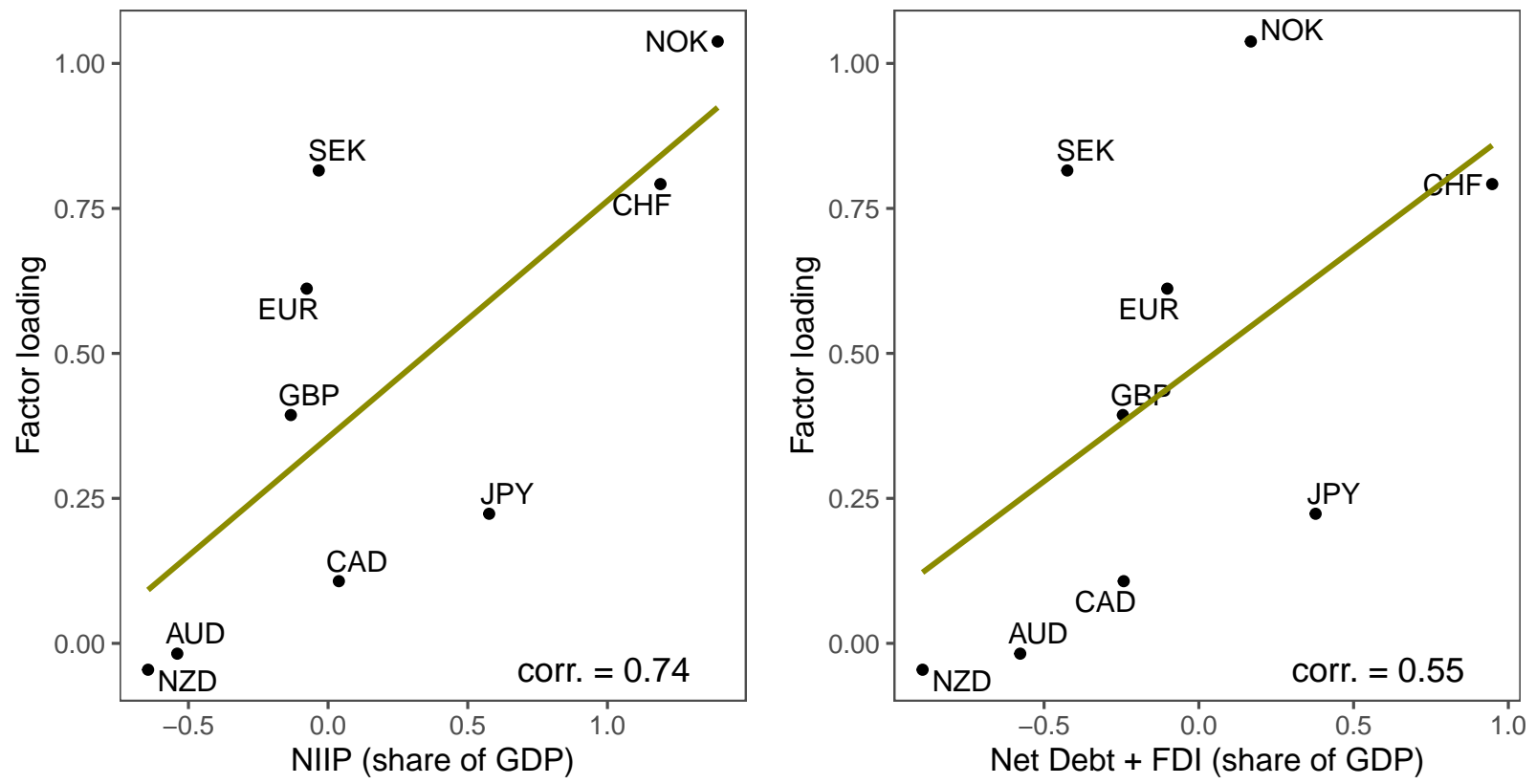
Figure 14: Options risk-reversal

This figure presents the relative pricing of calls and puts on currencies as measured by the risk-reversal defined as the 25-delta call minus put implied volatilities for options of 1 year maturity.

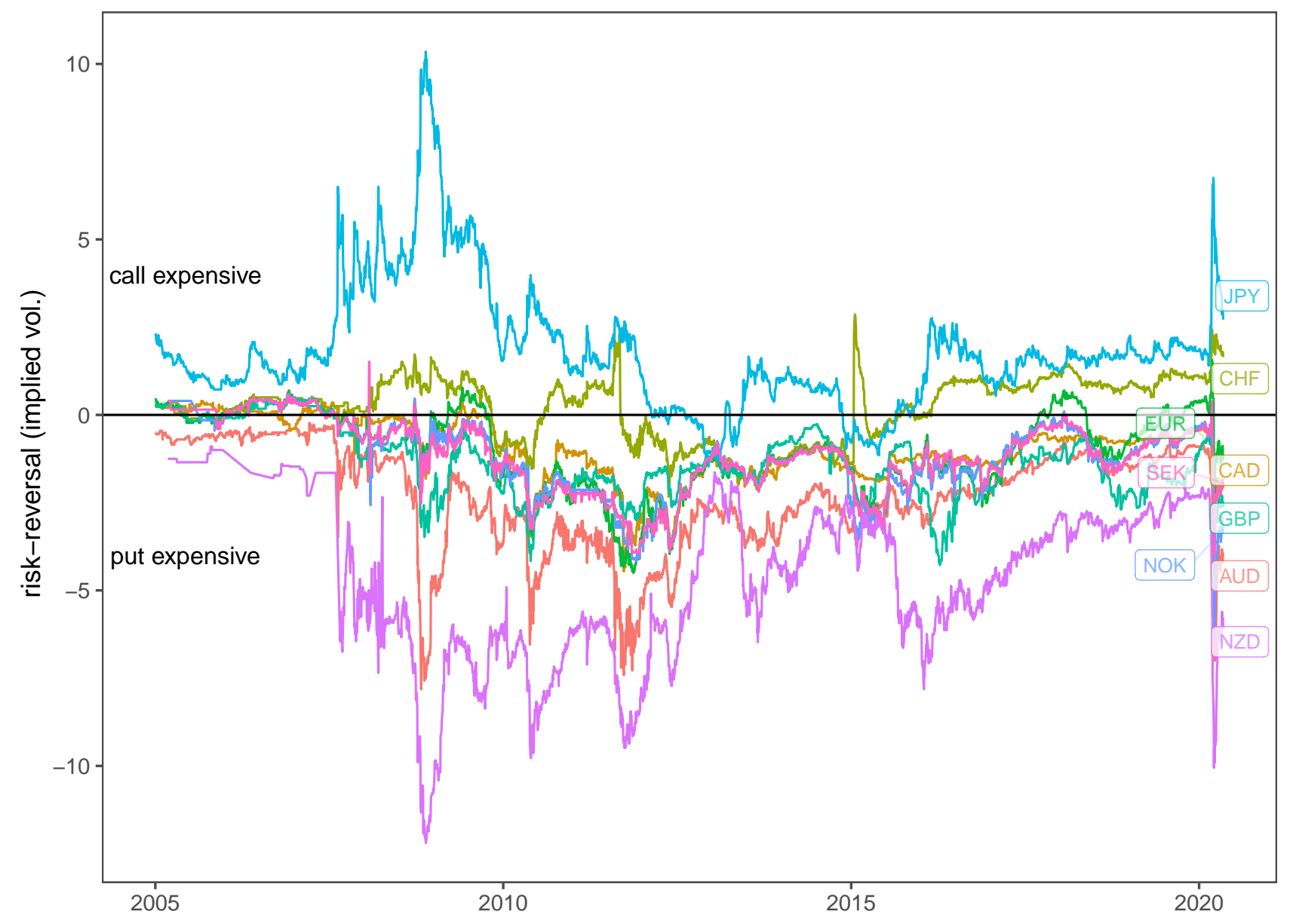


Figure 15: Conditional and unconditional option risk-reversals

This figure presents the relative pricing of calls and puts on currencies relative to countries' external imbalances. Panel A shows the average risk-reversal defined as call minus put implied volatilities for 25-delta, 1-year maturity options. Panel B shows the coefficients $\beta_{i}$ from estimating single-factor models of changes in risk-reversal regressed on the mean absolute magnitudes of risk-reversals. The sample comprises monthly data from January 2008 to April 2020.

Panel A. Unconditional risk-reversal
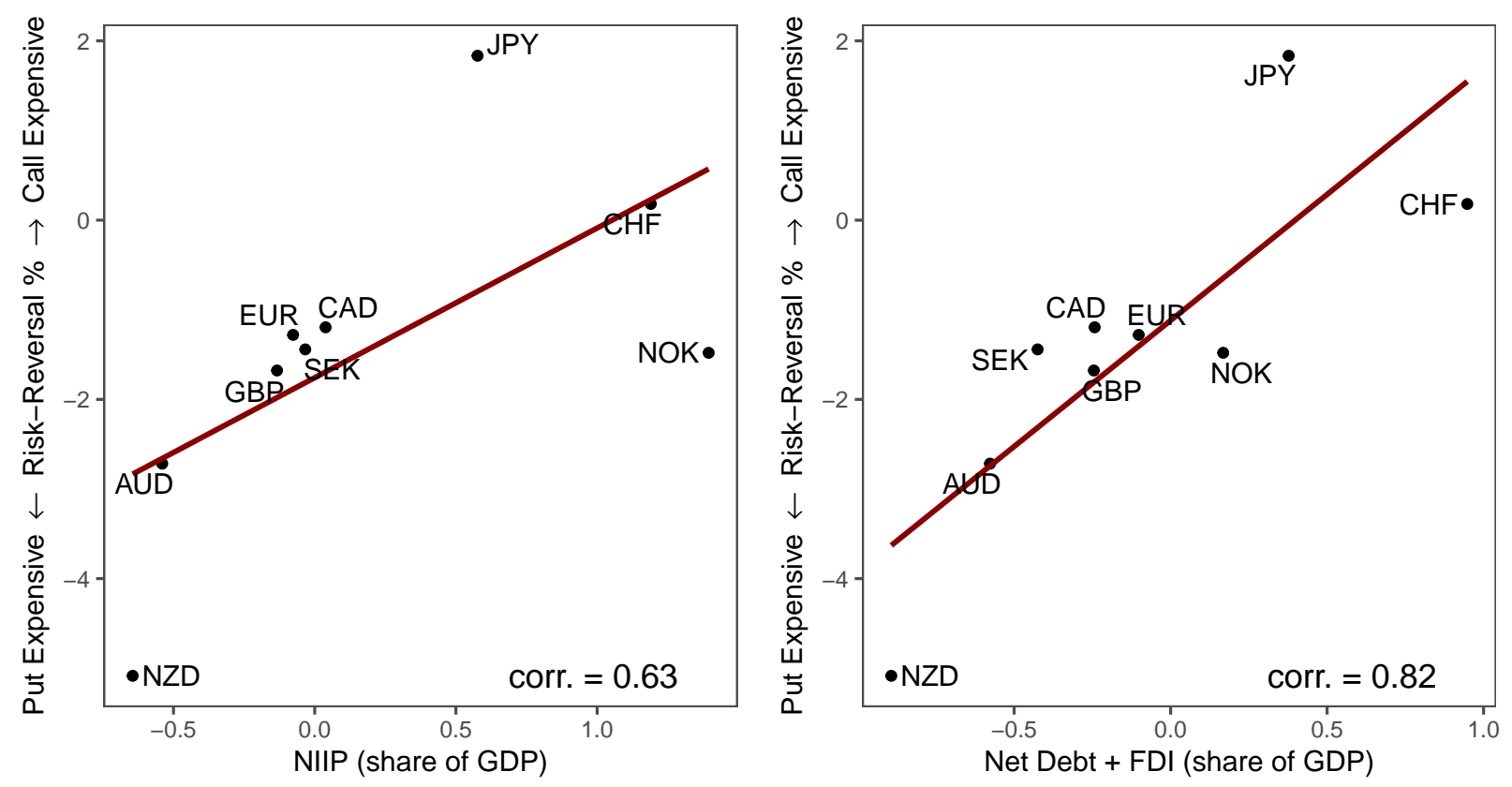

Panel B. Factor loadings of risk-reversal
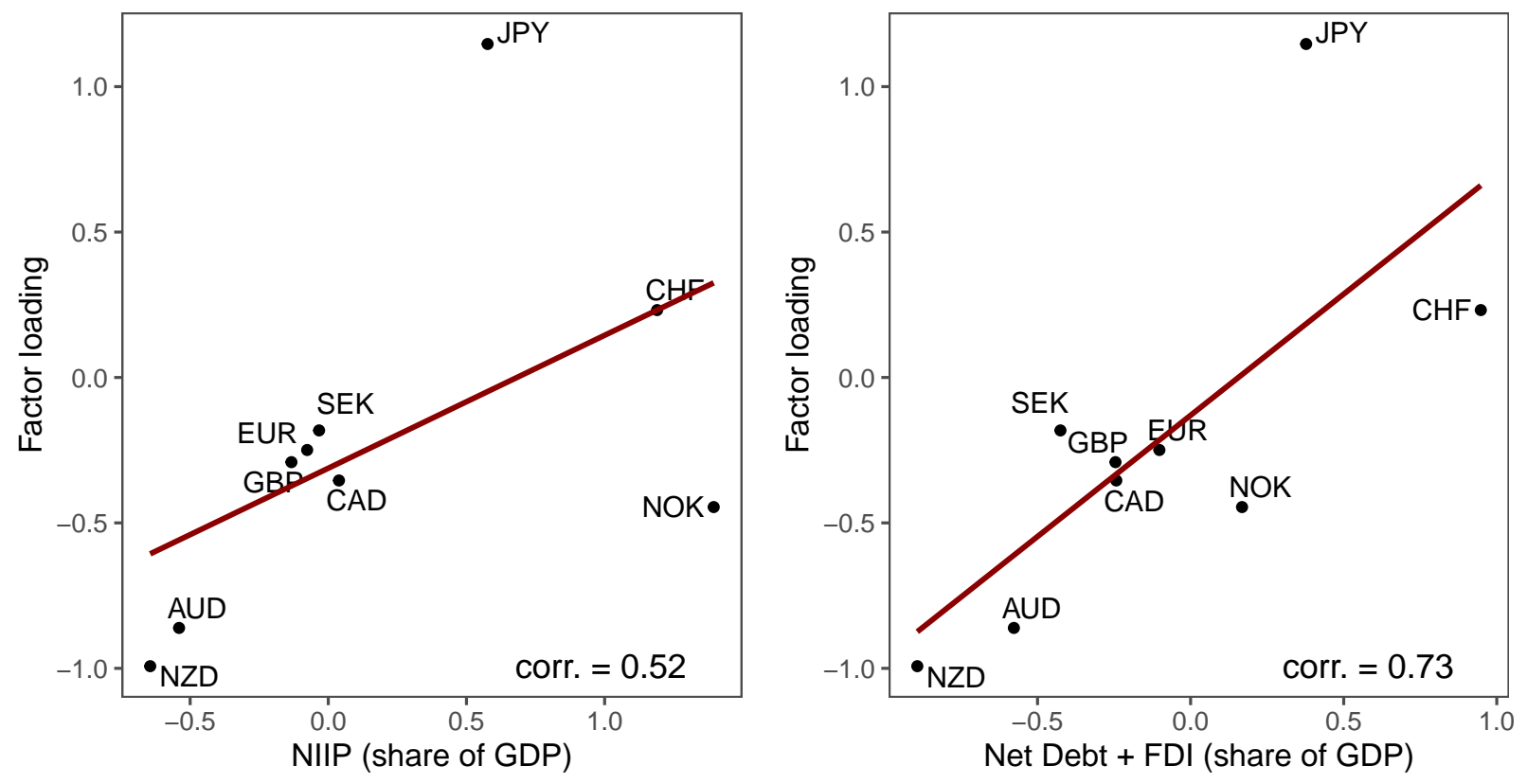
Table 1: Regulatory requirements on currency mismatch and hedging estimates

This table presents regulatory requirements on currency mismatch and hedging estimates across G10 currency countries. Column 1 describes the minimum currency match requirement between assets and liabilities in pensions given by the OECD 2019 Survey of Investment Regulation of Pension Funds. "Prudence rule" indicates no strict rules. However, regulations suggest "prudent investment". Column 2 indicates whether a country's insurance sector falls under Solvency II Directives. Column 3 presents additional hedging estimates from the Australian Bureau of Statistics 2017 Survey on Foreign Currency Exposure and Japanese insurance company investor disclosures.

\begin{tabular}{|c|c|c|c|}
\hline & $\begin{array}{c}\text { Pension: } \\
\text { Min. currency match }\end{array}$ & $\begin{array}{c}\text { Insurance: } \\
\text { Under Solvency II }\end{array}$ & Hedging estimates \\
\hline Australia & Prudence rule & & $\begin{aligned} \text { Debt assets: } & 59 \% \\
\text { Debt liab.: } & 80 \% \\
\text { Equity assets: } & 22 \%\end{aligned}$ \\
\hline Austria & $70 \%$ & $\mathrm{Y}$ & \\
\hline Belgium & & $\mathrm{Y}$ & \\
\hline Canada & Prudence rule & & \\
\hline Switzerland & $70 \%$ & & \\
\hline Germany & $70 \%$ & $\mathrm{Y}$ & \\
\hline Denmark & $80 \%$ & $\mathrm{Y}$ & \\
\hline Spain & & $\mathrm{Y}$ & \\
\hline Estonia & $50 \%$ & $\mathrm{Y}$ & \\
\hline Finland & $70 \%$ & $\mathrm{Y}$ & \\
\hline France & & $\mathrm{Y}$ & \\
\hline United Kingdom & & $\mathrm{Y}$ & \\
\hline Greece & $70 \%$ & $\mathrm{Y}$ & \\
\hline Ireland & & $\mathrm{Y}$ & \\
\hline Italy & $70 \%$ & $\mathrm{Y}$ & \\
\hline Japan & & & Life Insurers: $>50 \%$ \\
\hline Lithuania & & $\bar{Y}$ & \\
\hline Luxembourg & $70 \%$ & $\mathrm{Y}$ & \\
\hline Latvia & $80 \%$ & $\mathrm{Y}$ & \\
\hline Netherlands & & $\mathrm{Y}$ & \\
\hline Norway & $70 \%$ & & \\
\hline \multicolumn{4}{|l|}{ New Zealand } \\
\hline Portugal & $70 \%$ & $\mathrm{Y}$ & \\
\hline Slovak Republic & $70 \%-95 \%$ & $\mathrm{Y}$ & \\
\hline Slovenia & & $\mathrm{Y}$ & \\
\hline Sweden & $80 \%-100 \%$ & & \\
\hline United States & Prudence rule & & \\
\hline
\end{tabular}


Table 2: Summary Statistics

The sample comprises monthly data for all G-10 currencies (excluding the USD) between January 2008 and April 2020. A currencies' cross-currency bases is the spread between the exchange rate implied currency risk-free rate and the actual risk-free rate. The absolute cross-currency basis is the absolute value of this number. The annualized currency excess return is the difference between the log 12 month forward rate and the log spot exchange rate in 12 months. NIIP, Debt, FDI, Equity and GDP are measured quarterly and provided by the International Financial Statistics (IFS) from the IMF.

\begin{tabular}{lrrrr}
\hline \hline & Mean & Std. Dev. & Min & Max \\
\hline Cross-currency basis (bps) & -8.24 & 18.39 & -92.15 & 42.11 \\
Absolute cross-currency basis (bps) & 14.18 & 14.32 & 0.01 & 92.15 \\
Annualized currency excess returns (pct) & 0.01 & 0.11 & -0.39 & 0.35 \\
5-year minus 1-year basis spread (bps) & 2.56 & 11.41 & -48.95 & 60.75 \\
NIIP / GDP & 0.14 & 0.65 & -0.85 & 2.49 \\
Net Debt + FDI / GDP & -0.08 & 0.56 & -1.14 & 1.66 \\
Equity / GDP & 0.08 & 0.36 & -0.74 & 2.00 \\
Current Account / GDP & 0.01 & 0.02 & -0.04 & 0.05 \\
\hline \hline
\end{tabular}


Table 3: External imbalances and cross-currency bases (2008-2020)

The following table presents panel regressions of monthly average cross-currency bases on measures of external imbalances. The sample includes G10 currencies from January 2008 to April 2020. Standard errors are clustered by currency.

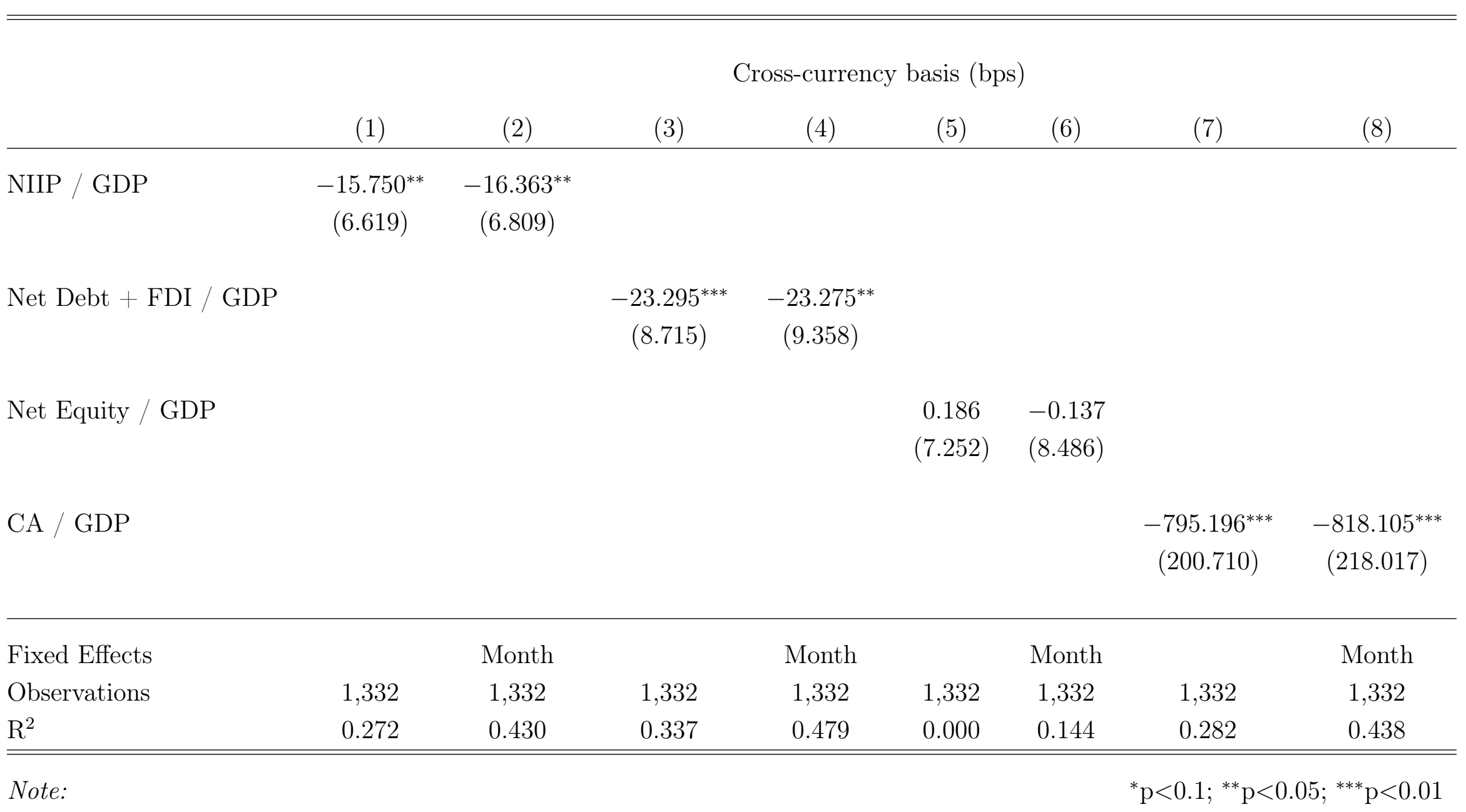


Table 4: External imbalances and cross-currency bases (2000-2020)

The following table presents panel regressions of monthly average cross-currency bases on measures of external imbalances. The sample period is from 2000 to 2020. Standard errors are clustered by currency.

Cross-currency basis (bps)

\begin{tabular}{lcccc} 
& $(1)$ & $(2)$ & $(3)$ & $(4)$ \\
\hline NIIP / GDP & $-13.520^{* * *}$ & $-12.822^{* * *}$ & & \\
& $(4.158)$ & $(4.898)$ & & \\
Net Debt + FDI / GDP & & & \\
& & & $-12.973^{*}$ & $-13.923^{* *}$ \\
& & & $(6.619)$ & $(6.798)$
\end{tabular}

$\stackrel{c}{\circledR}$

Net Equity / GDP

$\begin{array}{ll}-4.043 & -0.342 \\ (7.379) & (8.138)\end{array}$

CA / GDP

$$
\begin{array}{cc}
-452.982^{* * *} & -512.825^{* * *} \\
(136.827) & (117.830)
\end{array}
$$

\begin{tabular}{|c|c|c|c|c|c|c|c|c|}
\hline $\mathrm{R}^{2}$ & 0.229 & 0.466 & 0.156 & 0.446 & 0.006 & 0.267 & 0.141 & 0.444 \\
\hline
\end{tabular}


Table 5: Single factor model bases and exchange rates

This table presents regression results from a single factor model of changes in cross-currency bases and spot exchange rates:

$$
\Delta y_{i, t}=\alpha_{i}+\beta_{i} \bar{\Delta} b_{t}+\varepsilon_{i, t}
$$

where $\Delta y_{i, t}$ represents the change in the variable of interest for country $i$ in date $t$ and $\bar{\Delta} b_{t}=(1 / N) \sum_{j=1}^{N}\left|b_{j, t}\right|-\left|b_{j, t-1}\right|$ is the average change in the mean absolute magnitude of countries' cross-currency bases. The sample comprises monthly data from January 2008 to April 2020.

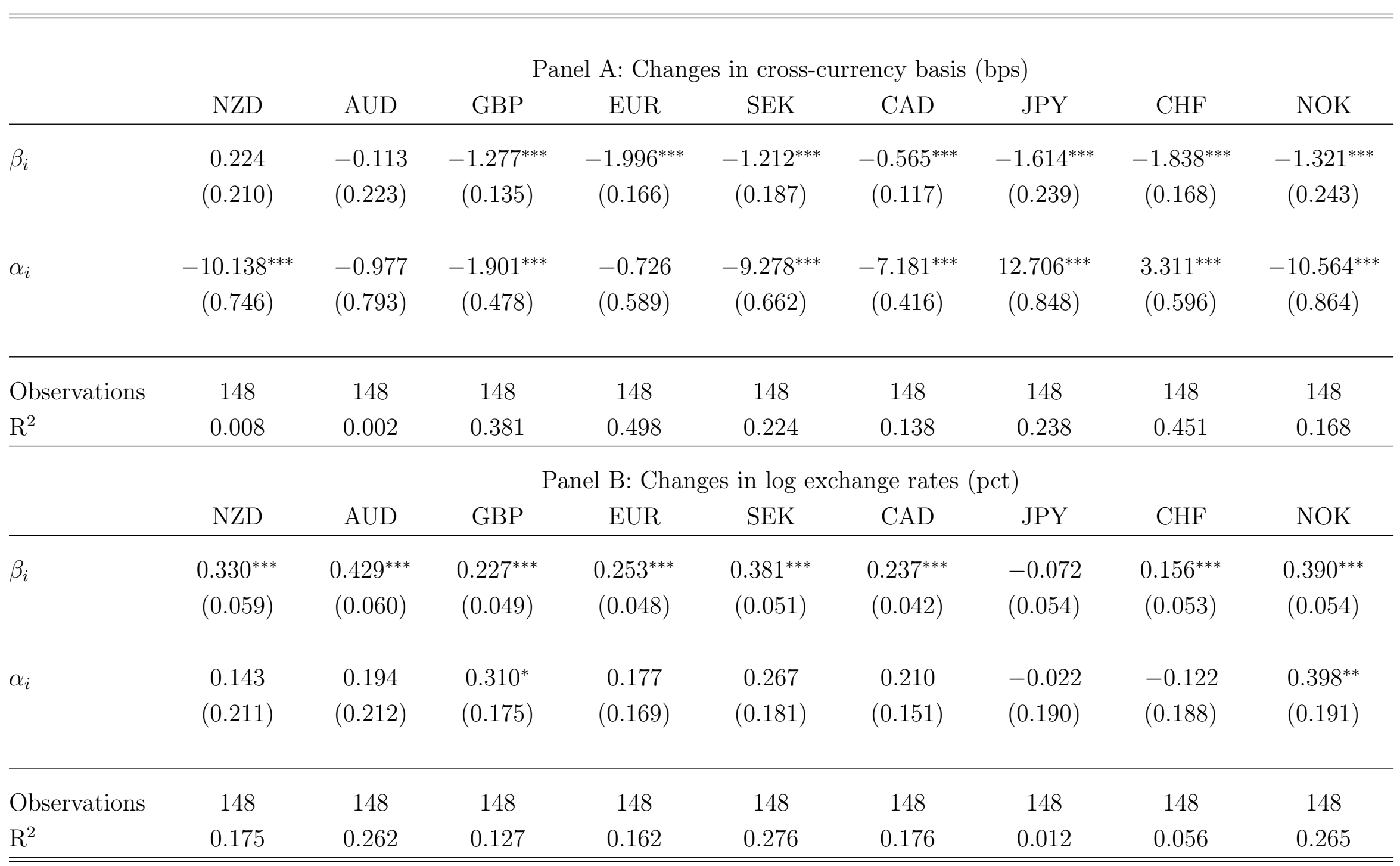


Table 6: Single factor model of the cross-country bases term spread

This table presents regression results from a single factor model of changes in cross-currency bases term spread:

$$
\Delta s_{i, t}=\alpha_{i}+\beta_{i} \bar{\Delta} b_{t}+\varepsilon_{i, t}
$$

where $\Delta s_{i, t}$ represents the change in the 5 -year minus 1-year cross-country term spread for country $i$ in $t$ and $\bar{\Delta} b_{t}=(1 / N) \sum_{j=1}^{N}\left|b_{j, t}\right|-$ $\left|b_{j, t-1}\right|$ is the average change in the mean absolute magnitude of countries' cross-currency bases. The sample comprises monthly data from January 2008 to April 2020.

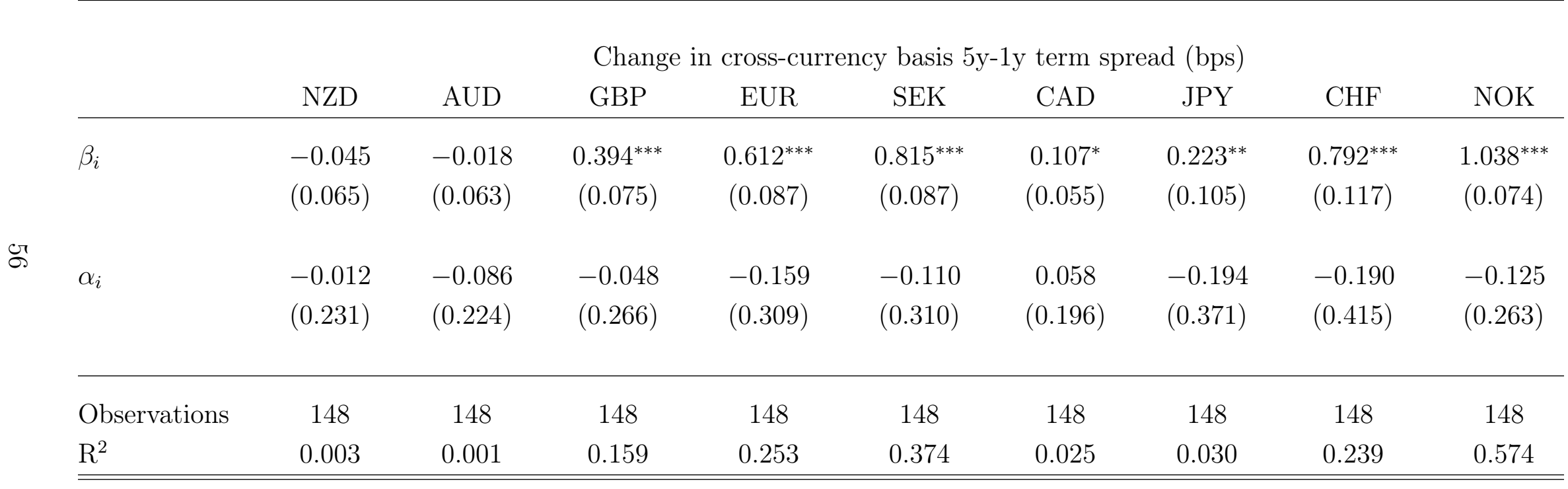

Note: 
Table 7: External imbalances and option risk-reversal

The following table presents panel regressions of monthly average option risk-reversal on measures of external imbalances. The option risk-reversal is defined as the implied volatilities of call minus put of options with one-year maturity and 25-delta. The sample includes G10 currencies from January 2008 to April 2020. Standard errors are clustered by currency.

option risk-reversal

\begin{tabular}{|c|c|c|c|c|c|c|c|c|}
\hline & (1) & $(2)$ & $(3)$ & $(4)$ & $(5)$ & $(6)$ & $(7)$ & $(8)$ \\
\hline NIIP / GDP & $\begin{array}{c}1.562^{*} \\
(0.842)\end{array}$ & $\begin{array}{c}1.526^{*} \\
(0.892)\end{array}$ & & & & & & \\
\hline Net Debt + FDI / GDP & & & $\begin{array}{c}2.657^{* * *} \\
(0.971)\end{array}$ & $\begin{array}{c}2.652^{* * *} \\
(1.006)\end{array}$ & & & & \\
\hline
\end{tabular}

\begin{tabular}{|c|c|}
\hline Net Equity / GDP & $\begin{array}{cc}-0.753 & -0.921 \\
(0.794) & (0.828)\end{array}$ \\
\hline
\end{tabular}

$\mathrm{CA} / \mathrm{GDP}$

$56.130^{*} \quad 59.279^{*}$

$(29.269) \quad(30.723)$

\begin{tabular}{|c|c|c|c|c|c|c|c|c|}
\hline Fixed Effects & & Month & & Month & & Month & & Month \\
\hline Observations & 1,332 & 1,332 & 1,332 & 1,332 & 1,332 & 1,332 & 1,332 & 1,332 \\
\hline $\mathrm{R}^{2}$ & 0.260 & 0.365 & 0.426 & 0.547 & 0.022 & 0.155 & 0.137 & 0.274 \\
\hline
\end{tabular}

Note:

${ }^{*} \mathrm{p}<0.1 ;{ }^{* *} \mathrm{p}<0.05 ;{ }^{* * *} \mathrm{p}<0.01$ 


\section{Appendix \\ -For online publication only-}

\section{A Appendix to Section 2}

\section{A.1 Extension: Endogenous Hedge Ratio}

In the following appendix, we extend the benchmark model in section 2 to allow for an endogenous hedge ratio $h$ and show the Propositions 1 through 3 hold in a model in which the Japanese investor's optimal hedge ratio responds endogenously to the forward rate.

We consider the hedging decision of the Japanese representative investor. We assume the Japanese investor exhibits mean-variance utility over her wealth in yen in period 2:

$$
\max _{h} h X_{D, 1}\left(1+r_{D, 1}\right) F_{1,2}+(1-h)\left(1+r_{D, 1}\right) X_{D, 1} \mathbb{E}\left[S_{2}\right]-\frac{\gamma}{2}\left((1-h)\left(1+r_{D, 1}\right) X_{D, 1}\right)^{2} V_{2}
$$

where (to re-iterate) $F_{1,2}$ is the one-period forward exchange rate in yen per dollar, and $S_{t}$ is the period $t$ spot exchange rate. $V_{2}=\operatorname{Var}\left[S_{2}\right]$ is the variance of the period 2 exchange rate.

We take first order conditions of (13) with respect to $h$ and simplify the result to show:

$$
h=1-\frac{\mathbb{E}\left[S_{2}\right]-F}{\gamma\left(1+r_{D, 1}\right) X_{D, 1} V_{2}} .
$$

Equation (14) has a very natural interpretation. The Japanese representative investor prefers to hedge her net dollar exposure if the dollar exchange rate is expected to move against her position. Moreover, the Japanese investor hedges a larger fraction of her net dollar asset position if she is more risk averse (higher $\gamma$ ) or if the total volatility of her portfolio in local currency is higher (higher $\left.\left(1+r_{D, 1}\right) X_{D, 1} V_{2}\right)$.

The equilibrium is now described equations (6), (7), (8) and equation (14). In this extended model, we solve for $b_{1}, F_{1,2}, S_{1}$ as well as $h$ in terms of the risk-free rate in each country, the excess demand for dollars and the exchange rate volatility $V_{2}$. 


\section{A.2 Extension: A Three-Period Model}

We start by describing the actions of the Japanese investor, which determines the demand for dollars in the forward market maturing in period 2 and 3. To re-iterate, the Japanese investor has a net external position $X_{D, 1}$ that now matures in period 3 . In period 1 , the Japanese investor wants to hedge an exogenous fraction $h$ of her external imbalance in each period. Hence, she initially demands:

$$
-h X_{D, 1}\left(1+r_{D, 1}\right)\left(1+r_{D, 2}\right)
$$

dollars in the forward market maturing in period 3.

In period 1, the Japanese investor can either purchase forward dollars maturing in period 3 , or she can purchase forward dollars maturing in period 2 and then roll her forward position to period 3. Let $\eta$ denote the share the Japanese position hedged by buying dollars in the forward market in period 1 and maturing in period 3. Hence, the Japanese investor demands $-\eta h X_{D, 1}\left(1+r_{D, 1}\right)\left(1+r_{D, 2}\right)$ forward dollars at the forward exchange rate of $F_{1,3}$ yen per dollar. The Japanese investor hedges the remaining $1-\eta$ share of her desired hedge position by buying $-(1-\eta) h X_{D, 1}\left(1+r_{D, 1}\right)$ forward dollars maturing in period 2 at the forward exchange rate $F_{1,2}$.

In period 2, the Japanese investor faces uncertainty in her hedging demand: With probability $\pi$, she decides to hedge a fraction $h_{L}$ of her total position, and with probability $1-\pi$ she decides to hedge a fraction $h_{H}$ of her total position. Ultimately, the Japanese investor demands:

$$
-\left(h_{k}-\eta h\right) X_{D, 1}\left(1+r_{D, 1}\right)\left(1+r_{D, 2}\right)
$$

dollars forward in period 2 and maturing in period $3 . h_{k}$ denotes the investor's total hedging demand for $k=L, H$. Denote the forward exchange rate for these contracts by $F_{2,3}$.

The swap trader provides liquidity in the forward exchange rate markets, and prices forward contracts taking into account uncertainty in the Japanese investor's hedging demand. The swap trader continues to face balance sheet costs $\kappa$ on her capital devoted to providing liquidity in the swap market. For simplicity, we assume the swap trader starts each period 
with wealth $W$, and can invest $I_{t}$ in an outside option in each period. The outside option provides a one period return of $G(I)$ where the function form of $G(I)$ is given in section 2 .

In period 1, the swap trader decides how much capital to devote towards providing liquidity in one-period forward markets, providing liquidity in the two-period forward market, or investing in the outside option in order to maximize expected discounted profits. Let $b_{1}^{(2)}$ denote the cross-currency basis on the two-period exchange rate forward in period 1:

$$
b_{1}^{(2)}=\frac{1}{2}\left(\frac{F_{1,3}}{S_{1}} \Pi_{t=1}^{2}\left(1+r_{D, t}\right)-\Pi_{t=1}^{2}\left(1+r_{Y, t}\right)\right) .
$$

Note, we divide the right-hand side by 2 to express the cross-currency basis in "per period" terms.

Letting the subscripts $\{2, L\}$ and $\{2, H\}$ denote quantities and prices in period 2 when the investor hedging demand equals $h_{L}$ and $h_{H}$, respectively, we can express the swap trader's problem as:

$$
\begin{aligned}
& \max _{q_{1}^{(1)}, q_{2, L}^{(1)}, q_{2, H}^{(1)}, q_{1}^{(2)}} \underbrace{\frac{-b_{1} q_{1}^{(1)}}{1+r_{Y, 1}}+\frac{\pi\left(-b_{2, L} q_{2, L}^{(1)}\right)+(1-\pi)\left(-b_{2, H} q_{2, H}^{(1)}\right)}{\left(1+r_{Y, 1}\right)\left(1+r_{Y, 2}\right)}}_{\text {Profits from 1-period forwards }}+\underbrace{\frac{-2 b_{1}^{(2)} q_{1}^{(2)}}{\left(1+r_{Y, 1}\right)\left(1+r_{Y, 2}\right)}}_{\text {Profits from 2-period forwards }} \\
& \underbrace{\frac{G\left(I_{1}\right)}{1+r_{Y, 1}}+\frac{\pi G\left(I_{2, L}\right)+(1-\pi) G\left(I_{2, H}\right)}{\left(1+r_{Y, 1}\right)\left(1+r_{Y, 2}\right)}}_{\text {Profits from other investment }} .
\end{aligned}
$$

where:

$$
\begin{aligned}
I_{1} & =W-\kappa\left|q_{1}^{(1)}+q_{1}^{(2)}\right| \\
I_{2, k} & =W-\kappa\left|q_{2, k}^{(1)}+q_{1}^{(2)}\left(1+r_{Y, 1}\right)\right| \text { for } k \in\{L, H\} .
\end{aligned}
$$

Note that the swap trader's period 1 position $q_{1}^{(2)}$ grows to $q_{1}^{(2)}\left(1+r_{Y, 1}\right)$ in period 2 .

Taking first order conditions of the swap trader's problem with respect to amount of capital devoted to 1-period forwards yields a familiar result: The cross-currency basis in each period and state of the world is proportional to the total swap trader position in that 
period and state:

$$
\begin{aligned}
b_{1} & =-\kappa^{2}\left(q_{1}^{(1)}+q_{1}^{(2)}\right) \\
b_{2, k} & =-\kappa^{2}\left(q_{2, k}^{(1)}+q_{1}^{(2)}\left(1+r_{Y, 1}\right)\right) \text { for } k \in\{L, H\} .
\end{aligned}
$$

Taking first order conditions with respect to $q_{1}^{(2)}$ yields :

$2 b_{1}^{(2)}=-\kappa^{2}\left(q_{1}^{(1)}+q_{1}^{(2)}\right)\left(1+r_{Y, 2}\right)-\pi \kappa^{2}\left(q_{2, L}^{(1)}+q_{1}^{(2)}\left(1+r_{Y, 1}\right)\right)-(1-\pi) \kappa^{2}\left(q_{2, H}^{(1)}+q_{1}^{(2)}\left(1+r_{Y, 1}\right)\right)$.

We plug the first order conditions with respect to $q_{1}^{(1)}, q_{2, L}^{(1)}$, and $q_{2, H}^{(1)}$ into the first order condition with respect to $q_{1}^{(2)}$ to derive equation (9).

Equations (15) and (16) reveal the one-period cross-currency bases depend only on the total swap trader position in each period. In each period $t$, the swap trader must hold a total position $q_{t}$ that ultimately produces the demanded quantity of forward dollars.

\section{B Carry trade on cross-currency term structure}

Following Du et al. (2019) that documents a trading strategy that exploits the maturity term structure of cross-currency basis, we show that the forward-starting cross-currency basis carry strategy has cross-sectional return variation that is aligned with external imbalances. We

calculate the 1-year-forward-1-year cross-currency basis carry strategy ${ }^{24}$ return that captures the roll-down and carry of the term-premia capture strategy strategy. Fig. A1 shows that the unconditional and conditional returns are related to external imbalances. Consistent with Du et al. (2019), we find that the position of lending AUD against JPY in forward basis swaps $^{25}$ has one of the highest carry returns, reflecting the upward sloping term structure in absolute value discussed in the main text. The negative factor loading of this position shown

\footnotetext{
${ }^{24}$ The position involves in the promise of lending dollar against foreign currency cash collateral in one-years time for the period of one year.

${ }^{25}$ Lend AUD versus JPY position is equivalent to entering into a buy AUD/sell JPY spot position and simultaneously sell AUD/buy JPY forward. It is also known as a pay JPY vs receive AUD floating coupon position.
} 
in panel $\mathrm{B}$ is also consistent with the observed basis widening and term structure inversion during crisis periods. 
Figure A1: Conditional and unconditional cross-currency basis carry trade

Panel A plots the unconditional return of lend dollar position in 1y-forward-1y cross-currency basis swap from 2008 to 2020 versus measures of external imbalances. Panel B shows the coefficients $\beta_{i}$ from single-factor models of the carry trade return: $\Delta r x_{i, t}=\alpha_{i}+\beta_{i} \overline{\Delta b}_{t}+\varepsilon_{i, t}$, where $\Delta r x_{i, t}$ is the realized 1-year-forward-1-year return for country $i$ at date $t$ and $\overline{\Delta b}_{t}$ is the the mean absolute deviation of countries' cross-currency bases.

Panel A. Unconditional forward cross-currency basis carry return (bps):
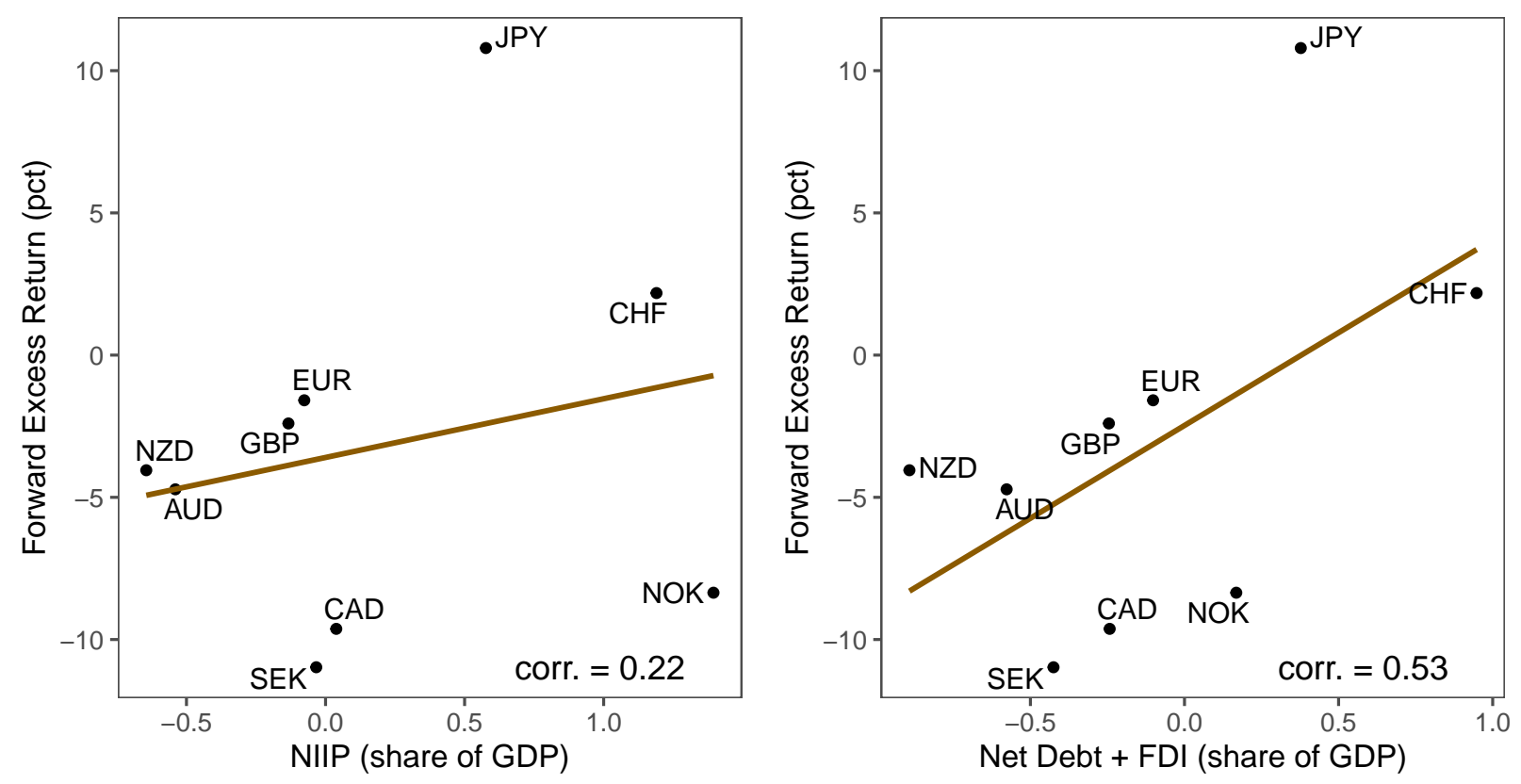

Panel B. Factor loadings of forward cross-currency basis carry returns (bps)
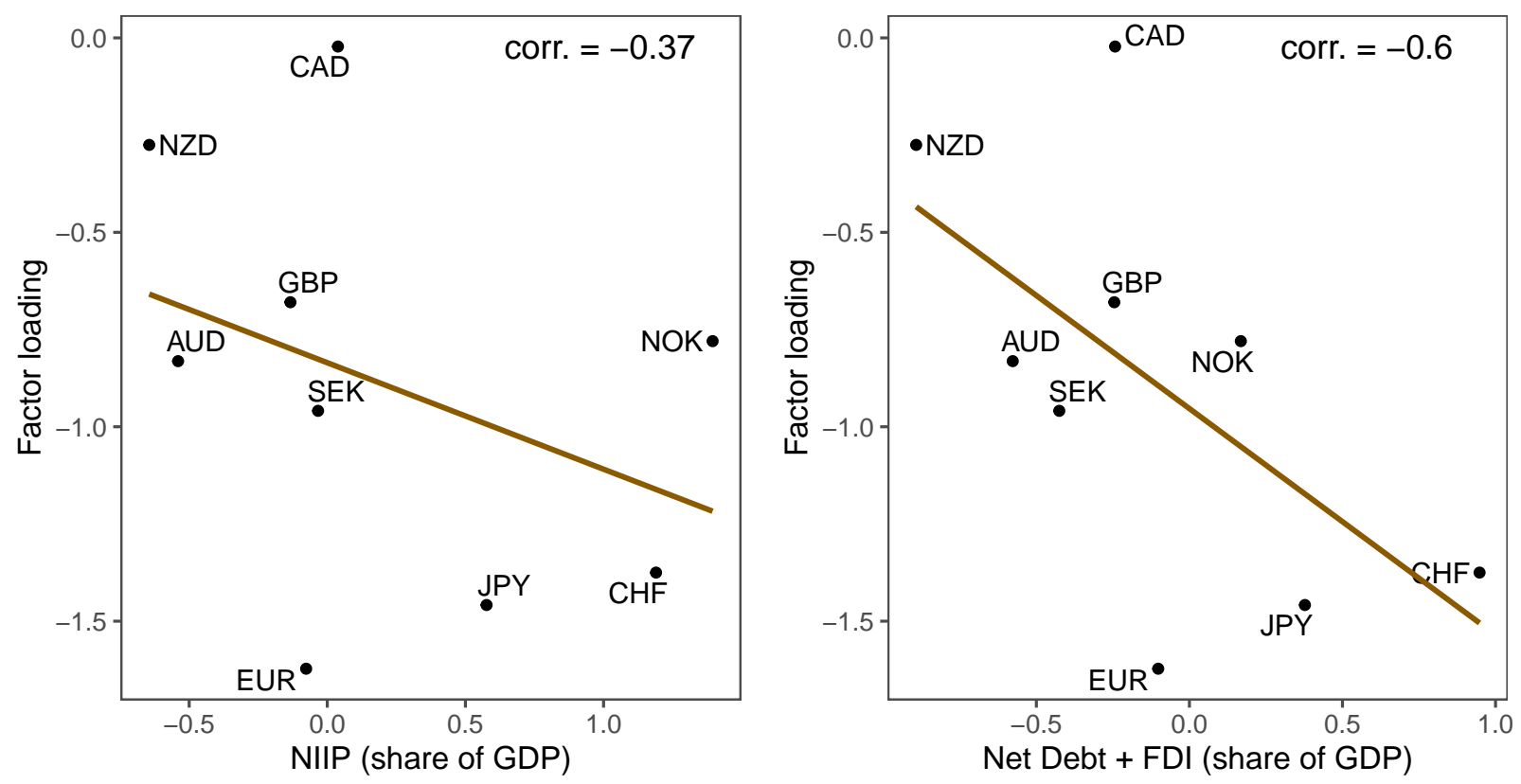
Table A1: Single factor model of basis carry trade

This table presents regression results from single factor models of the cross-currency bases carry trade:

$$
\Delta y_{i, t}=\alpha_{i}+\beta_{i} \overline{\Delta b}_{t}+\varepsilon_{i, t}
$$

where $\Delta s_{i, t}$ is the 1 -forward-1y cross-currency basis carry trade realized PNL for country $i$ in date $t$ and $\bar{\Delta} b_{t}=(1 / N) \sum_{j=1}^{N}\left|b_{j, t}\right|-\left|b_{j, t-1}\right|$ is the average change in the absolute magnitude of countries' cross-currency bases. The sample comprises monthly data from January 2010 to April 2019.

1-year-forward-1-year basis term carry trade realized PNL in basis points

\begin{tabular}{ccccccccccc} 
& NZD & AUD & GBP & EUR & SEK & CAD & JPY & CHF & NOK \\
\hline$\beta_{i}$ & $-0.611^{* *}$ & $-0.582^{*}$ & -0.428 & $-1.571^{* *}$ & $-1.186^{* * *}$ & $-0.576^{* * *}$ & $-1.950^{* * *}$ & $-1.729^{* * *}$ & -0.834 \\
& $(0.295)$ & $(0.295)$ & $(0.408)$ & $(0.628)$ & $(0.389)$ & $(0.195)$ & $(0.574)$ & $(0.537)$ & $(0.504)$
\end{tabular}

\begin{tabular}{lcccccccccc}
$\alpha_{i}$ & $-5.999^{* * *}$ & $-6.183^{* * *}$ & 1.209 & 2.584 & $-8.664^{* * *}$ & $-11.156^{* * *}$ & $16.579^{* * *}$ & $5.650^{* * *}$ & $-4.881^{* * *}$ \\
& $(0.821)$ & $(0.821)$ & $(1.136)$ & $(1.749)$ & $(1.083)$ & $(0.542)$ & $(1.598)$ & $(1.494)$ & $(1.404)$ \\
\hline Observations & 124 & 124 & 124 & 124 & 124 & 124 & 124 & 124 & 124 \\
$\mathrm{R}^{2}$ & 0.034 & 0.031 & 0.009 & 0.049 & 0.071 & 0.067 & 0.086 & 0.078 & 0.022 \\
\hline \hline
\end{tabular}

Note: 